\title{
Monitoring and repair of defects in ultrasonic additive manufacturing
}

\author{
Nadimpalli, Venkata Karthik; Karthik, G. M.; Janakiram, G. D.; Nagy, Peter B.
}

Published in:

International Journal of Advanced Manufacturing Technology

Link to article, DOI:

10.1007/s00170-020-05457-w

Publication date:

2020

Document Version

Peer reviewed version

Link back to DTU Orbit

Citation (APA):

Nadimpalli, V. K., Karthik, G. M., Janakiram, G. D., \& Nagy, P. B. (2020). Monitoring and repair of defects in ultrasonic additive manufacturing. International Journal of Advanced Manufacturing Technology, 108, 1793-1810. https://doi.org/10.1007/s00170-020-05457-w

\section{General rights}

Copyright and moral rights for the publications made accessible in the public portal are retained by the authors and/or other copyright owners and it is a condition of accessing publications that users recognise and abide by the legal requirements associated with these rights.

- Users may download and print one copy of any publication from the public portal for the purpose of private study or research.

- You may not further distribute the material or use it for any profit-making activity or commercial gain

- You may freely distribute the URL identifying the publication in the public portal 


\title{
Monitoring and Repair of Defects in Ultrasonic Additive Manufacturing
}

\author{
Venkata Karthik Nadimpalli ${ }^{1,2 *}$, G. M. Karthik ${ }^{3}$, G.D. Janaki Ram ${ }^{3}$, Peter B. Nagy ${ }^{1}$ \\ ${ }^{1}$ Department of Aerospace Engineering and Engineering Mechanics, \\ University of Cincinnati, Cincinnati, OH 45221, USA \\ ${ }^{2}$ Department of Industrial Engineering, J.B. Speed School, University of Louisville, Louisville, KY 40217, USA \\ ${ }^{3}$ Department of Metallurgical and Materials Engineering, Indian Institute \\ of Technology Madras, Chennai 600036, Tamil Nadu, India
}

\begin{abstract}
Ultrasonic Additive Manufacturing (UAM) involves ultrasonic welding of similar or dissimilar metal foils on top of a base substrate. UAM can produce solid consolidated structures, however, under certain processing conditions, inter-layer defects such as delamination/kissing bonds (Type-1) and inter-track (Type-2) defects may occur. Ultrasonic nondestructive evaluation (NDE) is well-suited for monitoring the quality of UAM builds. In this study, ultrasonic NDE is used to monitor the evolution of Type-1 defects in a UAM component divided into two zones. The first represents the base/build interface comprising of the first few layers on the base substrate and the second region represents the bulk of the UAM stack. The base/build interface is prone to delamination with layer build up referred to as Type-1a defects. The quality of the stack also reduces with layer build up thus forming partial bonds referred to as Type-1b defects. A mechanism for the formation and evolution of Type- 1 defects was proposed based on NDE and optical microscopy. While Type-1 defects can be monitored, and remedied, Type- 2 defects are more catastrophic and are difficult to repair. To overcome these defects in UAM, we propose a novel solid-state repair technique using friction stir processing (FSP). The use of FSP ensures that the microstructural advantages of UAM are retained while improving the part quality. Two modes of FSP were designed - FSP from above for repair of inter-track (Type-2) defects and FSP from below the base for repair of base/build (Type-1a) defects. The results of this study
\end{abstract}

${ }^{*}$ Corresponding author, Tel.: +1-352-214-5569; E-mail address: nadimpvk@uc.edu (V. K. Nadimpalli) 
pave the way towards the development of an integrated solid-state additive manufacturing system with UAM as the primary bonding mechanism and FSP as an enhancement and repair tool.

Keywords: UAM, NDE, Additive manufacturing, Friction stir processing, imperfect interfaces

\section{Introduction}

Ultrasonic Additive manufacturing (UAM) is a layer-by-layer metal solid-state bonding process which is commonly used in conjunction with a Computer Numerical Control (CNC) mill. A $20 \mathrm{kHz}$ ultrasonic horn or sonotrode vibrates at amplitudes varying from 10 to $50 \mu \mathrm{m}$. A high normal force is applied to facilitate solid-state ultrasonic welding of thin metal foils on a base substrate. UAM can produce functional components with embedded optical sensors or electronics, parts with fully enclosed internal cooling channels or heat exchangers, parts in multimaterials or composites [1-6]. The quality of UAM parts is dependent on several factors including process parameters (amplitude of vibration, clamping force, welding speed, and substrate temperature), surface condition of the foil, substrate, and sonotrode, geometry of the build [7-8].

UAM can produce good quality functional components but these components are sometimes prone to defects and delamination typical to UAM. Several studies focus on developing optimal process parameters for UAM and then eliminating defects through post-weld treatments [9-17]. To form a good bond, there must be enough power input into the ultrasonic weld while at the same time ensuring that already bonded interfaces are not pulled apart due to excessive vibration or power input [11]. Defects in UAM are labeled as Type-1 for inter-layer defects and Type-2 for inter-track defects $[5,16]$. While most of UAM literature is focused on 
reducing Type- 1 defects, fewer studies focus on Type- 2 defects. It is useful to classify Type- 1 defects into two subgroups, Type-1a for base/build delamination and Type-1b for defects within the stack. Nadimpalli et al. [18] found that this distinction is important because the base/build interface is prone to delamination. In fact, this is one of the limiting factors while building components with height-to-width ratio $>2[15,17]$. Since UAM part quality is geometry dependent, the optimal build parameters need to be changed with build height. Hehr et al. [11] reported on the effects of build compliance on bond quality and suggested power compensation. While this works for Type-1b defects, it might exacerbate Type-1a defects and doesn't address Type-2 defects. It is important to consider Type-1a defects since the base could also form a part of the final UAM component.

The low process temperatures in UAM allow for monitoring of Type-1 defects during part fabrication using ultrasonic NDE techniques [18, 19]. Further, Type-I defects are characteristically planar and ultrasonic NDE is well-suited for such defects. In previous work Nadimpalli et al. [19] has designed an in-situ monitoring setup with a fully enclosed high frequency (5-10 MHz) NDE transducer below the base substrate. Preliminary results indicated that Type-1a defects are common even if they are not physically visible to the naked eye since the UAM component is strongly bonded to the base but parts of it are delaminated at the base/build interface. An interfacial spring model-based inversion technique was proposed which considers each UAM interface to be acting like a spring under ultrasonic NDE vibrations. There is ample evidence that suggests the modeling of UAM components as imperfect interfaces [1922]. The stiffness of such interface layers can be measured in-situ layer by layer and can provide a quantitative evaluation of UAM interfaces. Offline ultrasonic NDE can also be used to calculate the elastic constants of UAM components and image internal features such as Type-1a 
defects [23]. NDE studies need to be backed up with destructive correlation which can be achieved through the means of a push-pin test proposed by Zhang et al. [24]. Other mechanical tests such as lap-shear and tensile have been shown to be correlated to area under push-pin loaddisplacement curves which represents the work done in extruding 10-15 UAM layers in a 3-point bend configuration.

Both Type-1 and Type-2 defects in UAM components need to be eliminated either through improving the process or healed after manufacturing, so that UAM components can be used for structural applications $[12,13]$. Post-process heat treatment of UAM components was shown to be effective in increasing bond quality and reducing Type- 1 defects, but heat treatment can't fix Type-2 defects. Due to the variability in processing conditions that affect bond quality, it is imperative to develop a methodology to heal/repair the typical defects in UAM. Given that the primary advantage of UAM is solid-state processing, it is meaningful to consider only solidstate techniques for repair of defects in UAM parts. Several other friction-based solid-state additive manufacturing techniques like friction deposition [25-26], friction lap-seam welding [27] and Friction Stir Additive Manufacturing (FSAM) [28-29] have been proposed and demonstrated for various materials. All these methods involve a layer by layer manufacturing or joining of material to near-net shape and have been suggested for making larger size components compared to UAM. Out of the existing friction-based solid-state processes, FSAM, which is essentially layer-by-layer Friction Stir Welding (FSW), appears to be most promising. Mishra et al. [30] proposed Friction Stir Processing (FSP) as a solid-state tool for improving the microstructural characteristics of materials. FSP has been demonstrated for creating fine grain microstructure, surface and bulk composites, in-situ multi-material synthesis and for healing crack and surface defects. In section 2 of this paper, we present the mechanism for Type-1a 
(base/build interface) delamination and propagation along with a qualitative nondestructive evaluation of Type I defects using both in-situ and offline ultrasonic NDE. In section 3, we propose Friction Stir Processing as a novel repair tool to completely heal both Type-1a and Type-2 defects. Type-1a defects are necessarily healed after UAM processing while Type-2 defects can be healed in-situ. We thus propose for the first time an integrated solid-state process with UAM as the primary bonding mechanism and FSP as a repair and refinement tool.

\section{Monitoring Evolution of Defects in UAM}

\subsection{In-situ and offline ultrasonic nondestructive evaluation}

Two possible approaches of in-situ monitoring were previously proposed and tested [18, 19], one from above the UAM stack and the other from below the base plate. Monitoring from below was found to be a practical approach which can be used for continuous online quality monitoring. The primary challenge was to ensure that the addition of the in-situ monitoring system does not alter the quality of UAM components. Supports were required to raise the base plate to accommodate the in-situ monitoring system. Supports along the bonding and vibration directions were tested and it was found that raising the base plate alters the quality of UAM components as compared to the reference. Thus, a new set up was implemented wherein the ultrasonic NDE sensor was entirely embedded in a large solid block of aluminum as shown in Figure 1. The sensor was changed from contact mode to immersion so that the vibrations produced during UAM processing do not affect the coupling. High temperature lubricant oil was chosen as the coupling agent since it is stable up to $500{ }^{\circ} \mathrm{C}$. Through mechanical testing, it was shown previously that the quality of UAM components built on this set up were comparable to that of reference components built with no transducer beneath them. 
Using the optimized in-situ sensor setup, UAM components were built with 30 layers of Al 6061-H18 foils (150 $\mu \mathrm{m}$ thick) on an Al 6061 base plate. Using $5000 \mathrm{~N}$ normal force, 85 $\mathrm{mm} / \mathrm{s}$ welding speed and $100{ }^{\circ} \mathrm{C}$ baseplate preheating, six test components were made by varying the amplitude of sonotrode vibration in the range of 30 to $37 \mu \mathrm{m}$. The UAM experiments were conducted on Soniclayer R7200 system located at Fabrisonic. The in-situ NDE sensor was a 10 MHz, $6 \mathrm{~mm}$ unfocused delay line immersion probe. In-situ continuous monitoring was performed so that information was captured throughout the bonding process. In an earlier work, Nadimpalli et al. [19] observed that high frequency noise corrupts the NDE response during UAM, which creates both an amplitude modulation and a phase shift in the signal. The bonding time for a $100 \mathrm{~mm}$ long single track is around 1.2 seconds with a dwell time of $70 \mathrm{~ms}$ in the central $6 \mathrm{~mm}$ section that is illuminated by $10 \mathrm{MHz}$ ultrasound. With a pulse repetition frequency (PRF) of $20 \mathrm{kHz}, 1400$ waveforms are collected and saved in this time interval. The amplitude and frequency modulation of the NDE sensor $(10 \mathrm{MHz})$ by the ultrasonic horn $(20 \mathrm{kHz})$ are beyond the scope of this current paper. The vibration amplitudes produced by the NDE sensor are in the sub-nanometer scale and wouldn't conceivably affect the UAM bond quality. Since we are continuously monitoring, we can focus on the interval after UAM bonding before a new layer begins during which time the NDE sensor is able to measure the UAM component with no interference. During this time, the UAM system snips the tape and prepares for the next layer with the whole process taking around 10 seconds. Capturing the data after each layer of UAM bonding provides information about the evolution of quality with layer build up. Figure 2 shows two components of vibration amplitude 36 and $37 \mu \mathrm{m}$. The lower amplitude (black) has good bonding and the higher amplitude (red) has a delamination at the base/build interface. The ultrasound first travels through the oil followed by the base. It then hits the base/build interface 
which might have a reflection depending on the quality. The transmitted ultrasound travels through the UAM stack and gets reflected from the top layer. The reverberations at the start of the oil buffer are edited out so that the features of interest can be focused on. To compare the signals from two components, the reflection from the oil/base interface is used to line up the signals so that the time delay can be compared. With increasing layer number, the signal appearing from the top of the UAM stack appears after a time delay due to the addition of extra propagating distance. In the delaminated component, from the $17^{\text {th }}$ layer an indication for base/build interface delamination appears that grows stronger. At the same time, there is also propagation through the base/build interface evidenced by the signal from the top of the stack.

To extract bond quality information from the experimental signals, it is important to model wave propagation through UAM components. Modeling the experimentally observed phenomenon requires a distinction between the base/build interface and the rest of the stack. A framework for modeling wave propagation through UAM components has been presented in Nadimpalli et al. [19]. UAM components have a clear distinction between bulk foil layer and a small interface layer where bonding occurs. Thus, a wave propagation model was developed with each UAM interface acting as a massless interfacial spring with finite stiffness as shown in Figure 3. The interfacial stiffness ( $\kappa$ ) represents the quality of the interface layer and is defined as $\kappa=\eta C_{11} / d$, where $\eta$ is an interfacial stiffness coefficient, $C_{11}$ is the modulus of the layer material, and $d$ is the layer thickness. The interfacial stiffness coefficient $(\eta)$ is a normalized, dimensionless coefficient which represents the quality of an imperfect layer.

A zero-stiffness layer indicates a free surface and an infinite-stiffness layer indicates a rigid boundary. Two interfacial stiffnesses $\kappa_{1}, \kappa$ represent the base/build interface and the average stiffness of each layer in the UAM stack respectively. A layer thickness $(d)$ of $150 \mu \mathrm{m}$ is 
considered so that the stiffness values can be compared to those of a single UAM layer. The interfacial spring stiffness has been used extensively in NDE literature as a measure of quality of imperfect interfaces [20-22]. A model-based inversion methodology was presented in Nadimpalli et al. which details the extraction of stiffness values from in-situ ultrasonic signals [19]. Figure 4 shows the two independent stiffness values $\kappa_{1}, \kappa$ for the six components. As the vibration amplitude increases, the stack stiffness increases until $36 \mu \mathrm{m}$ and then decreases. The base/build interface stiffness on the other hand decreases with increasing amplitude. The component with $37 \mu \mathrm{m}$ amplitude shows a stark reduction in the base/build interface stiffness from layer 17 onward as seen from the raw signals data presented in Figure 2. UAM literature widely agrees that the optimal UAM bonding conditions need to have enough energy input into the component to create a good bond but not too much so that it causes a delamination either at the base/build interface (Type-1a defect) or within the UAM stack (Type-2 defect).

\subsection{Base/build interface evolution}

The base/build interface is most prone to delamination with layer build up. Delamination at this interface is often a limiting factor on build height. For certain applications, the base is also a part of the structure of interest. In such a case, it is necessary to measure and monitor the quality of the base/build interface. For applications where the base is not a part of the structure of interest, a certain amount of base/build delamination is acceptable if the structure remains firmly attached to the base. In both cases, it is imperative to understand the mechanism of base/build interface delamination. Ultrasonic NDE is a useful tool to measure the quality of UAM components not only in-situ but also after fabrication. This is henceforth referred to as offline NDE, since the UAM component is removed from the machine. The top surface of a UAM component is rough and its texture is dependent on sonotrode roughness (typically 7-20 
$\mu \mathrm{m} R_{\mathrm{a}}$ ). This level of surface roughness limits the frequency of measurement due to surface attenuation. Hence, offline NDE is best performed from below the base substrate. The six UAM components were hence immersed in a SONIX acoustic microscopy tank filled with water and a delay line immersion unfocused transducer of frequency $5 \mathrm{MHz}$ was used for inspection. Ultrasonic A-scan signals gathered from below the base have three distinct features, the oil/base interface, the base/build interface, and the top of the UAM stack as can be observed from Figure 2. Ultrasonic C-scans were obtained by gating a region of interest that corresponds to a height within the component while scanning across the other two axes as shown in Figure 5. A $100 \mu \mathrm{m}$ resolution was used along both the scanning and stepping axes to generate an image of the base/build interface henceforth referred to as the reflection image, and an image from the top of the UAM stack henceforth referred to as the transmission image. In existing literature, the mechanism of base/build interface delamination has not been thoroughly explored.

Before bonding the first layer, the base was machined and retextured to facilitate better bonding conditions. It was experimentally observed that this produces better results as far as Type-1a defects are concerned. Figure 6 shows C-scan images that are presented in grey scale with white indicating a higher value. The reflection image depicts the quality of the base/build interface, with a lower reflection representing better quality. The transmission image depicts the quality of the UAM stack, with a higher transmission representing better quality. Base/build delamination can be observed in both the reflection and transmission images. In the reflection image, good bonding corresponds to a black region, while in the transmission image, good bonding corresponds to a white region. At each point. The reflection images indicate that the base/build delamination increases with vibration amplitude and can be far more prevalent than what is visible to the naked eye. In the components built with $30,31 \mu \mathrm{m}$ vibration amplitude, the 
base/build delamination occurs on the inside and is localized to a small region (below the red circles). The red circles indicate the location of the in-situ monitoring NDE sensor for comparison with the interfacial stiffness values. Components 31-37 $\mu \mathrm{m}$ have delamination starting from either one or both long edges. In Figure 4, up to amplitude $36 \mu \mathrm{m}$, no delamination was visible, but that is primarily because of the small field of view. It should be noted that all these components were firmly attached to the base and the component couldn't be manually separated. The component with $37 \mu \mathrm{m}$ vibration amplitude has Type-1a defects of two types, starting from the edge and regions of partial bonding that don't appear to have started on the edge. Based on the acoustic microscopy images, components 32, 34 and $36 \mu \mathrm{m}$ should have shown at least a small refection during in-situ monitoring. It is hence conceivable that after removal from the heated base plate of the UAM system, the components relax and the delamination spreads further inward.

Due to the visualization provided by offline ultrasonic NDE, we can distinguish between three kinds of Type-1a defect evolution. The first is due to low energy input which leads to poor bonding. It occurs primarily on the inner side of the UAM weld and likely occurred during building the first few layers. The second kind of defect starts from the edge and occurs due to the vibration of the UAM stack with build height. The base/build interface acts as a stress concentration which takes the load from the vibrating stack. It is hence prone to delamination starting on the edges. In several components these cracks start from the edge and propagate inward along a circular arc. The UAM bonding process itself is akin to $20 \mathrm{kHz}$ cyclic fatigue. All evidence indicates that these interfaces were once bonded and then delaminated due to cyclic loading. The third kind of defect is due to excessive energy input during building the first few layers that leads to a damaged base/build interface which also occurs on the inside of the UAM 
weld. Thus, to maintain a good base/build interface, the vibration amplitude must be optimal during building the first few layers followed by which there must be a reduction in vibration amplitude to reduce the load on the base/build interface. But this approach is not feasible since it leads to Type $1 \mathrm{~b}$ defects which will be discussed in further detail below.

\section{$2.3 \quad$ UAM stack quality}

UAM stack quality is dependent on geometry as substrate stiffness affects the ultrasonic energy input. The effect of build compliance on power drawn during UAM has been reported by Hehr et al. [11]. Optimum vibration amplitude is dependent on component geometry. In single track components, the vibration amplitude requires change after every layer with build height. This is referred to as an amplitude-compensated UAM component. Contrary to the quality of the base/build interface, it is important to increase the vibration amplitude so that the same amount of power is input into the UAM component. Figure 7 shows the cross section of 80-layer, 11.5 $\mathrm{mm}$ thick component built at $32 \mu \mathrm{m}$ vibration amplitude. The first $7.5 \mathrm{~mm}$ from the bottom have good layer bonding with no visible delamination (up to the dashed white line). In the remaining 4 $\mathrm{mm}$, several delamination defects are observed at interfaces between layers. These are referred to as Type- $1 \mathrm{~b}$ defects and are caused due to the insufficient power input into the UAM component.

To utilize vibration amplitude as a parameter to control and study UAM component quality, it is pertinent to establish the accuracy and resolution of the ultrasonic welder. For this purpose, a laser vibrometer was aimed at the weld-head of a Fabrisonic R200 UAM system and the vibration amplitude was measured (Appendix B). The R200 system is an experimental open architecture machine that is ideal for research and development. The percent amplitude setting is an operator input into the UAM system. The DUKANE iQ welder used in UAM allows for a $1 \%$ resolution which approximately corresponds to $0.5 \mu \mathrm{m}$ amplitude change. The average standard 
deviation measured with laser vibrometer at various amplitude setting levels was approximately $0.2 \mu \mathrm{m}$. This indicates that the control system is highly accurate and there is a clear distinction between vibration amplitude settings separated by $0.5 \mu \mathrm{m}$ or more. UAM components were also measured during welding and it was found that the control is equally good under load. After validating that the vibration amplitude of the horn is very close to the input value, the mechanism of Type- $1 \mathrm{~b}$ defect formation becomes evident. As the build height increases, the UAM structure is more compliant thereby requiring less power to keep the ultrasonic horn vibrating at the same amplitude.

To test the change in weld power with layer height, a test was conducted on the R200 system. UAM components with 25 layers of $150 \mu \mathrm{m}$ thick Al 6061 foils that are $76 \mathrm{~mm}$ long were manufactured with varying vibration amplitudes. The average power is a readout parameter on the DUKANE iQ welder. It represents the average power drawn by the ultrasonic horn to accurately maintain the vibration amplitude. Figure 8 a shows the changes in average weld power with layer height for varying vibration amplitudes. In each case, the power reduces with layer build-up. Figure $8 \mathrm{~b}$ plots the power normalized with square of the vibration amplitude. The normalized power at various amplitudes falls within a $+/-10 \%$ standard deviation at every layer height and follows a decreasing trend. In an amplitude compensated UAM build, the power does not reduce with build height thereby enabling similar ultrasonic energy input into each layer. The orange line represents the average of normalized power for all the vibration amplitudes. A linear fit has an excellent $\mathrm{R}$-squared value and indicates that the average power is decreasing with build height. The negative slope is representative of the compliance of the UAM stack while the intercept of the linear fit indicates the normalized power for the other bonding parameters (normal force, welding speed) and material. 
With in-situ monitoring, it is possible to quantify the change in modulus with layer build up in an amplitude-uncompensated UAM build. Figure 9 shows the modulus of various components calculated from the average stack interfacial stiffness. These components were built on the Fabrisonic R7200 UAM system located at Edison Welding Institute. With increasing amplitude, the stack modulus is higher and with increasing layer number, and the stack modulus steadily reduces. The component with $37 \mu \mathrm{m}$ vibration amplitude has a lower stack quality than the one with $36 \mu \mathrm{m}$ amplitude. For the first several layers, the $37 \mu \mathrm{m}$ amplitude inputs extra power into the component which causes Type-1a and Type-1b delamination. This is also evident from Figure 6 which shows the third kind of Type-1a defects that form due to excessive power input.

To validate the results from nondestructive evaluation, it is important to verify the results with destructive tests. Push-pin mechanical test has been widely used to evaluate the mechanical strength of UAM components. It involves pushing out a set of UAM layers in a three-point bend configuration. Push-pin specimen and test specifications were derived from Hopkins et al. [9]. Two modes of failure are typically observed, first is a premature failure at the base/build interface and second is a failure through a set of UAM layers. The former is primarily indicative of a poor base/build interface and does not necessarily indicate the quality of the stack. The latter represents the quality of the top few layers of the UAM stack. The different failure mechanisms are well documented in literature. Figure 10 shows the results of push-pin testing. The area under push-pin curves is the mechanical work required to push out a set of UAM layers. This represents the mechanical strength of the component and is combination of shear and tensile loading capability. As the vibration amplitude increases, the area under load-displacement curve increases until an amplitude of $36 \mu \mathrm{m}$ and then drastically reduces at an amplitude of $37 \mu \mathrm{m}$. The 
failure of the $37 \mu \mathrm{m}$ component occurred at the base/build interface and is not indicative of the quality of the entire stack. It is clear from these results that the destructive and nondestructive tests are well correlated. Another kind of UAM stack defect is the Type-2 or inter-track defect which occurs between adjacent tracks. Type- 2 defects will be discussed in further detail in Section 3 where we present a novel method of repairing Type-1a and Type-2 defects in UAM components.

\section{Repairing UAM Defects through Friction Stir Processing}

Friction stir processing (FSP) achieves microstructural refinement, densification, and homogeneity using a rotating tool. The microstructure and mechanical properties of the processed zone can be accurately controlled by optimizing the tool design, FSP parameters, and active cooling/heating. The depth of the processed zone can be adjusted by changing the length of the tool pin, with the depth ranging from several hundred micrometers to tens of millimeters. FSP does not change the shape and size of the processed components. For these reasons, FSP is an effective solid-state processing technique for achieving localized microstructural modification in metallic components. UAM distinguishes itself from other additive technologies because of its low temperature solid-state processing. UAM is uniquely suited for producing parts with enclosed internal cooling channels and embedded sensors as well as for producing parts in multimaterials and metal-matrix composites. Even dissimilar metals that are not metallurgically compatible can be combined to produce multi-material parts without embrittlement or cracking. Repairing defects in UAM components using traditional joining methods undercuts the advantages of using UAM. A solid-state processing technique like FSP is an excellent add-on to the UAM process for repairing cracks as well as refining existing microstructures. The two most commonly observed defects in UAM are, base/build interface defects (Type-1a) and inter-track 
defects (Type-2). FSP can be used to repair defects of both types. Repairing Type-1a defects can be carried out during component fabrication but it requires the removal of the base plate and would require some setup time. Type- 2 defects can be healed in between UAM layers by changing the weld head for an FSP tool. Type-1b defects are better addressed by changing the UAM process parameters. The UAM system is well equipped to facilitate tool changes since it utilizes a CNC milling operation between layers. Adding an FSP tool is a low-cost method to heal defects in-situ between layers as and when required. The process parameters utilized during FSP are presented in Table 1. Figure 11 shows a schematic of the friction stir tool used in the current study. A UAM sample after FSP is also shown in the figure.

\subsection{Repairing base/build delamination}

UAM components can be manufactured while having a good quality stack alongside a base/build interface delamination as observed in Section 2.2. If the UAM stack is the sole component of interest and the base can be discarded after manufacturing, then the repair of the base/build interface is often not required. However, when the base is a part of the component or when the delamination at the base/build interface interferes with satisfactory part fabrication, then repair is required. Base/build delamination also prevents the transmission of ultrasonic NDE signals and hence hinders in-situ monitoring. In-situ monitoring can give indication of Type-1a defects far before they become visible to the naked eye. Figure 12 shows an optical image of base/build delamination that is visible to the naked eye. The cross section shown is made of 80layer, $11.5 \mathrm{~mm}$ thick component built at $32 \mu \mathrm{m}$ vibration amplitude on a Fabrisonic R7200 UAM system. The same component is also shown in Figure 7 where the reduction in stack quality with layer build-up was discussed. Figure 13 shows a schematic of inverted UAM component with support blocks on either side. The length of tool pin is chosen such that it penetrates through the 
base and $2 \mathrm{~mm}$ (14 layers) into the UAM component. Figure 14 shows the optical micrograph of the cross-section after FSP. The crack developed at the base/build interface is completely healed. The regions marked 1 to 8 represent the interaction of the UAM component and FSP. The enlarged optical micrographs in these regions, clearly indicate the plastic deformation around the rotating tool as seen in Figure 14. Friction stir processing has completely healed the large delamination observed and refined the layered microstructure of the UAM component. The interfaces between layers are no longer visible under optical examination as they have been friction stirred around the tool.

Even though the delamination is visible to the naked eye, the extent of delamination is unknown, hence we performed acoustic microscopy to look inside the component. After removing from the UAM system the component was immersed into a SONIX acoustic microscope and scanned according to scan parameters discussed in Section 2.2 to generate a Cscan reflection image gated at the base/build interface. A color palette was applied for better visualization and Figure 15a shows the delamination visible to the naked eye. Unlike the components seen in Figure 6, the delamination has not propagated all the way to the center and is only on one side. This is because the vibration amplitude is low $(32 \mu \mathrm{m})$ and the amount of power into the component keeps decreasing with layer build-up. This causes the delamination to be localized to one corner of the component. Figure $15 \mathrm{~b}$ shows the reflection image after FSP processing. The white lines mark the FSPed region. The color palette for the two images is different but the important feature is the contrast between delaminated and well bonded regions. A low amplitude in the reflection image indicates a good bond and thus we can observe from the contrast that the delamination was completely healed in the region where friction stir processing was performed. Two kinds of Type-1 defects have opposing bonding criteria and optimizing 
UAM process parameters require a balance between the UAM stack quality (Type-1b) and base/build delamination (Type-1a).

\subsection{Repairing inter-track defects}

There have been a few attempts in literature to optimize the UAM process for minimizing Type-2 defects [16]. The Fabrisonic R7200 UAM system has a build area of $3.24 \mathrm{~m}^{2}$ while a single foil width is $25.4 \mathrm{~mm}$. The build height of UAM components is limited when the component consists of a single track. With multiple tracks, the build height can be significantly increased. For these reasons, it is critical to address Type-2 defects. The most typical approach to tackle Type- 2 defects relies on changing the overlap between adjacent foils to achieve good inter-track bonding. The mechanism of Type- 2 defect formation is through the lack of bond formation between adjacent tracks laid side-by-side. While an overlap region helps to reduce Type-2 defects, it might not entirely eliminate them. To illustrate the working of FSP, a test component of 40 layers and 3 tracks was built to have inter track defects, a typical Type-2 defect is shown in Figure 16. While it is possible to make components with limited Type-2 defects, when hundreds of inter-track regions are present across a large UAM component, it becomes tough to ensure that all the inter-track regions will be perfect. When it comes to Type- 1 defects, the bonding mechanism and defect evolution are well understood, and it is possible to expect reasonable bond quality in an amplitude compensated UAM build. With Type-2 defects, the reasonable expectation of bond quality might depend on several localized geometrical factors which are tough to control. This is a limiting factor for making large UAM components for structural applications.

UAM components often have several tracks laid one beside the other to make components larger than 1 inch along the vibration direction. Typically, these tracks have small 
overlap region to ensure that the tracks laid down beside each other have metallurgical bonding. This overlap region is often prone to crack initiation and propagation. FSP is particularly wellsuited to repair inter-track UAM defects. UAM is performed in conjunction with CNC milling wherein the weld head can be replaced with a CNC tool for machining components to a required dimension. This makes it possible to incorporate an FSP tool that can be programmed to move according to the existing $\mathrm{CNC}$ infrastructure. This provides the chance to repair inter-track regions after every few layers. Figure 17 shows the schematic of repairing UAM Type- 2 defects using FSP. Figure 18 shows the optical micrograph of the cross-section after FSP. The crack developed between the two adjacent UAM tracks is completely healed. The regions marked 1-8 represent the interaction of the UAM component and FSP. The enlarged optical micrographs in these regions, clearly indicate the plastic deformation around the rotating tool and show that the Type-2 defect is completely healed as seen in Figure 16. It can be observed that the inter-track defects as well as base/build delamination were entirely healed and the region where the process was performed had a homogenous quality throughout. Even if there is no clear indication of cracking, FSP of inter-track regions offers a microstructural and mechanical improvement in quality due to solid-state processing. There are several advantages of using FSP as a complimentary repair mechanism specifically to heal existing inter-track defects as well as to improve the quality of inter-track regions. FSP offers the unique advantage of being able to control the tool depth and thus the processing zone. A change in tool width is also possible which can be used on the complex geometries common in UAM. The results demonstrate the potential for a solid-state Additive Manufacturing system combining UAM as the primary bonding mechanism and FSP as a repair and refinement mechanism to be utilized in specific regions where the quality of components can be improved. 


\section{Conclusion}

The current study is aimed at developing methods for monitoring and repair of defects in UAM. Defects in UAM are classified into two kinds namely, Type- 1 and Type-2. Type- 1 defects are further divided into Type-1a and Type-1b defects. Type-1a defects occur at the base/build interface while Type-1b defects are inter-layer defects that occur at other locations within the UAM stack. Type-2 defects also occur within the stack but between two adjacent UAM tracks. Ultrasonic NDE is well suited for monitoring UAM defects. An in-situ continuous online monitoring ultrasonic NDE setup was designed and installed on a Soniclayer R7200 UAM system. Ultrasonic A-scan data was collected before, during and after each layer. A twoparameter wave propagation model previously developed in [19] was used to study the interaction of ultrasonic waves with UAM components. Each UAM interface between neighboring layers was modeled as an interfacial spring. Two independent stiffness coefficients are necessary to model wave propagation are base/build interface $\left(\eta_{1}\right)$ and bulk stack stiffness (१). A bond quality inversion methodology was used for continuous quality evaluation. Both kinds of Type-1 defects were measured which allows the understanding of the mechanism of evolution of Type-1 defects in UAM.

Acoustic microscopy (offline NDE) was utilized to map base/build interface delamination. The geometry of the component, location on base substrate and its dimension play a significant role in the initiation and propagation of this delamination. Among all the interfaces, the base/build interface is especially prone to delamination since it acts as a stress concentration during vibration. Ultrasonic NDE provides a physical visualization of the delamination which could be more catastrophic than is observable through visual examination. The mechanism of 
formation and evolution of Type-1a defects was proposed based on NDE results. Three kinds of Type-1a defects were identified and the reasons for formation of these defects were discussed.

UAM stack quality was also studied and the reduction in quality with layer build up was quantified. Type-1b defects form within the stack either due to low or excessive power input. Based on laser vibrometer studies, the UAM sonotrode in a Fabrisonic R200 research machine was calibrated. The DUKANE iQ welding controller maintains the average vibration amplitude close to the setpoint (1\% s.d.) in free air and during welding. Hence it becomes clear that with increasing build height, given that the amplitude at the sonotrode remains the same, less power is transmitted into the UAM weld. The average power drawn by the ultrasonic horn for various amplitude settings was presented which shows a decreasing trend as expected. These results agree with the UAM stack modulus measured by the in-situ monitoring setup. Type-1b defects of two kinds were examined. The defects caused by lower power are a systemic problem in UAM components and can be remedied by amplitude compensation with build height. Higher power input leads to a disruption of previous layer bonds and hence inter-layer defects.

Based on our understanding of the UAM defect evolution, Friction Stir Processing (FSP) was presented as a novel in-situ repair and refinement tool for UAM components. While inter track defects are repaired from the top of UAM stack, base/build delamination is repaired from below the base. To illustrate the working of FSP, a test component of 40 layers and 3 tracks was built to have inter track defects. Another test component was built with single track stacked with 80 layers and had base/build delamination. Friction Stir Processing repaired the defective zones in both test components as observed through optical and acoustic microscopy. There are several advantages of using FSP as a complimentary repair mechanism specifically to heal existing intertrack defects as well as to improve the quality of inter-track regions. The results of this work 
pave the way for the development of a solid-state additive manufacturing process with UAM as the primary bonding mechanism integrated with FSP as a repair and refinement tool.

\section{Acknowledgements}

This work was supported by Office of Naval Research grant ONR-BAA \#14-004-1110689 Cyber Enabled Manufacturing Systems, acoustic resonance techniques for online certification and offline qualification of metal based additive manufacturing technologies. The authors express gratitude to Mark Norfolk from Fabrisonics for lending us valuable machine time. We would also like to acknowledge Joe Vickers from the Rapid Prototyping Center for manufacturing the experimental setup. We thank Dr. Li Yang from the University of Louisville and Curtis Fox from University of Cincinnati for their valuable advice.

\section{References}

[1] Friel, R. J., \& Harris, R. A. (2013). Ultrasonic additive manufacturing-a hybrid production process for novel functional products. Procedia CIRP 6, 35-40.

[2] Li, J., Monaghan, T., Nguyen, T. T., Kay, R. W., Friel, R. J., \& Harris, R. A. (2017). Multifunctional metal matrix composites with embedded printed electrical materials fabricated by ultrasonic additive manufacturing. Composites Part B: Engineering 113, 342-354.

[3] Bournias-Varotsis, A., Wang, S., Hutt, D., \& Engstrøm, D. S. (2018). The Effect of Ultrasonic Additive Manufacturing on Integrated Printed Electronic Conductors. Electronic Materials Letters 14, 1-13.

[4] Hehr, A., Norfolk, M., Wenning, J., Sheridan, J., Leser, P., \& Newman, J. A. (2018). Integrating Fiber Optic Strain Sensors into Metal Using Ultrasonic Additive Manufacturing. JOM 70, 315-320.

[5] Yang, Y., Ram, G. J., \& Stucker, B. E. (2009). Bond formation and fiber embedment during ultrasonic consolidation. Journal of Materials Processing Technology 209, 4915-4924.

[6] Burns, J. R., Petrovic, B., Chandler, D., \& Terrani, K. A. (2018). Reactor physics phenomena in additively manufactured control elements for the High Flux Isotope Reactor. Annals of Nuclear Energy 115, 403-414. 
[7] Koellhoffer, S., Gillespie, J. W., Advani, S. G., \& Bogetti, T. A. (2011). Role of friction on the thermal development in ultrasonically consolidated aluminum foils and composites. Journal of Materials Processing Technology 211, 1864-1877.

[8] Sriraman, M. R., Babu, S. S., \& Short, M. (2010). Bonding characteristics during very high power ultrasonic additive manufacturing of copper. Scripta Materialia 62, 560-563.

[9] Hopkins, C. D., Wolcott, P. J., Dapino, M. J., Truog, A. G., Babu, S. S., \& Fernandez, S. A. (2012). Optimizing ultrasonic additive manufactured Al 3003 properties with statistical modeling. Journal of Engineering Materials and Technology 134, 011004.

[10] Sridharan, N., Gussev, M. N., Parish, C. M., Isheim, D., Seidman, D. N., Terrani, K. A., \& Babu, S. S. (2018). Evaluation of microstructure stability at the interfaces of Al-6061 welds fabricated using ultrasonic additive manufacturing. Materials Characterization 139, 249-258.

[11] Hehr, A., Wolcott, P. J., Wolcott, P. J., \& Dapino, M. J. (2016). Effect of weld power and build compliance on ultrasonic consolidation. Rapid Prototyping Journal 22, 377-386.

[12] Levy, A., Miriyev, A., Sridharan, N., Han, T., Tuval, E., Babu, S. S., \& Frage, N. (2018). Ultrasonic additive manufacturing of steel: Method, post-processing treatments and properties. Journal of Materials Processing Technology 256, 183-189.

[13] Sridharan, N., Gussev, M., Seibert, R., Parish, C., Norfolk, M., Terrani, K., \& Babu, S. S. (2016). Rationalization of anisotropic mechanical properties of Al-6061 fabricated using ultrasonic additive manufacturing. Acta Materialia 117, 228-237.

[14] Mariani, E., \& Ghassemieh, E. (2010). Microstructure evolution of $6061 \mathrm{O}$ Al alloy during ultrasonic consolidation: An insight from electron backscatter diffraction. Acta Materialia 58, 2492-2503.

[15] Robinson, C. J., Janaki Ram G. D., \& Stucker, B. E. (2011) Role of substrate stiffness in ultrasonic consolidation, International Journal of Rapid Manufacturing 2, 162-177.

[16] Obelodan, J., Janaki Ram, G. D., Stucker, B. E., \& Taggart, D. (2010) Minimizing defects between adjacent foils in ultrasonically consolidated parts, Journal of Engineering Materials and Technology 132, 1-8.

[17] Gibert, J. M., Fadel, G., \& Daqaq, M. F. (2013). On the stick-slip dynamics in ultrasonic additive manufacturing. Journal of Sound and Vibration 332, 4680-4695.

[18] Nadimpalli, V. K., Na, J. K., Bruner, D. T., King, B. A., Yang, L., \& Stucker, B. E. (2016). In-situ non-destructive evaluation of ultrasonic additive manufactured components. $27^{\text {th }}$ Annual International Solid Freeform Fabrication Symposium, 1557-1567.

[19] Nadimpalli, V. K., Yang, L., \& Nagy, P. B. (2018). In-situ interfacial quality assessment of Ultrasonic Additive Manufacturing components using ultrasonic NDE. NDT \& $E$ International 93, 117-130.

[20] Baik, J. M., \& Thompson, R. B. (1984). Ultrasonic scattering from imperfect interfaces: a quasi-static model. Journal of Nondestructive Evaluation 4, 177-196. 
[21] Nagy, P. B. (1992). Ultrasonic classification of imperfect interfaces. Journal of Nondestructive evaluation, 11, 127-139.

[22] Milne, K., Cawley, P., Nagy, P. B., Wright, D. C., \& Dunhill, A. (2011). Ultrasonic nondestructive evaluation of titanium diffusion bonds. Journal of Nondestructive Evaluation 30, 225-236.

[23] Foster, D. R., Dapino, M. J., \& Babu, S. S. (2013). Elastic constants of ultrasonic additive manufactured Al 3003-H18. Ultrasonics 53, 211-218.

[24] Zhang, C. S., Deceuster, A., \& Li, L. (2009). A method for bond strength evaluation for laminated structures with application to ultrasonic consolidation. Journal of Materials Engineering and Performance 18, 1124-1132.

[25] Dilip, J. J. S., Babu, S., Rajan, S. V., Rafi, K. H., Ram, G. J., \& Stucker, B. E. (2013). Use of friction surfacing for additive manufacturing. Materials and Manufacturing Processes 28, 189-194.

[26] Dilip, J. J. S., Janaki Ram, G. D., \& Stucker, B. E. (2012). Additive manufacturing with friction welding and friction deposition processes. International Journal of Rapid Manufacturing 3, 56-69.

[27] Kalvala, P. R., Akram, J., \& Misra, M. (2016). Friction assisted solid state lap seam welding and additive manufacturing method. Defence technology 12, 16-24.

[28] Sharma, A., Bandari, V., Ito, K., Kohama, K., Ramji, M., \& BV, H. S. (2017). A new process for design and manufacture of tailor-made functionally graded composites through friction stir additive manufacturing. Journal of Manufacturing Processes 26, 122-130.

[29] Palanivel, S., Nelaturu, P., Glass, B., \& Mishra, R. S. (2015). Friction stir additive manufacturing for high structural performance through microstructural control in an $\mathrm{Mg}$ based WE43 alloy. Materials \& Design 65, 934-952.

[30] Mishra, R. S., \& Ma, Z. Y. (2005). Friction stir welding and processing. Materials Science and Engineering: R: Reports 50, 1-78. 
Table 1: FSP process parameters

\begin{tabular}{|c|c|c|c|c|}
\hline \multicolumn{5}{|c|}{ FSP Process Parameters } \\
\hline $\begin{array}{c}\text { Rotation } \\
\text { speed (rpm) }\end{array}$ & $\begin{array}{c}\text { Traverse feed } \\
(\mathrm{mm} / \mathrm{min})\end{array}$ & $\begin{array}{c}\text { Dwell time } \\
(\mathrm{sec})\end{array}$ & $\begin{array}{c}\text { Shoulder } \\
\text { plunge }(\mathrm{mm})\end{array}$ & $\begin{array}{c}\text { Tool backward } \\
\text { tilt angle } \\
\text { (degrees) }\end{array}$ \\
\hline 1000 & 10 & 10 & 0.2 & 2 \\
\hline
\end{tabular}


a)

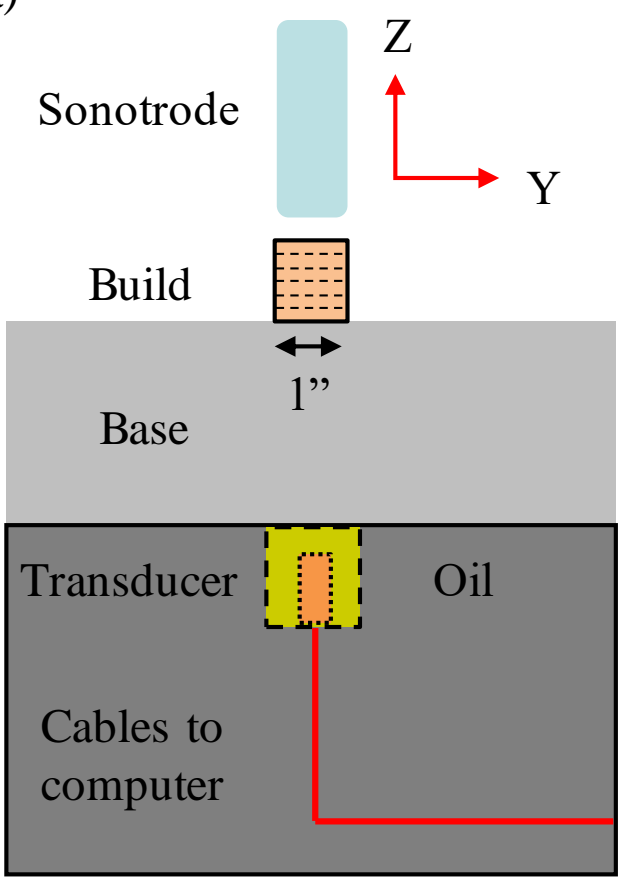

b)
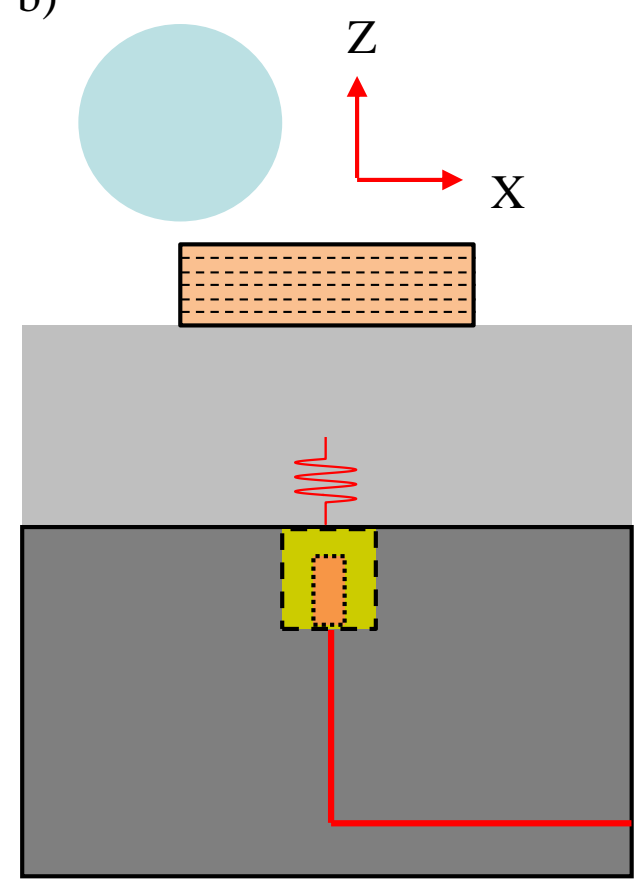

Figure 1: In-situ monitoring ultrasonic NDE setup with fully embedded sensor a) front view, b) side view. 


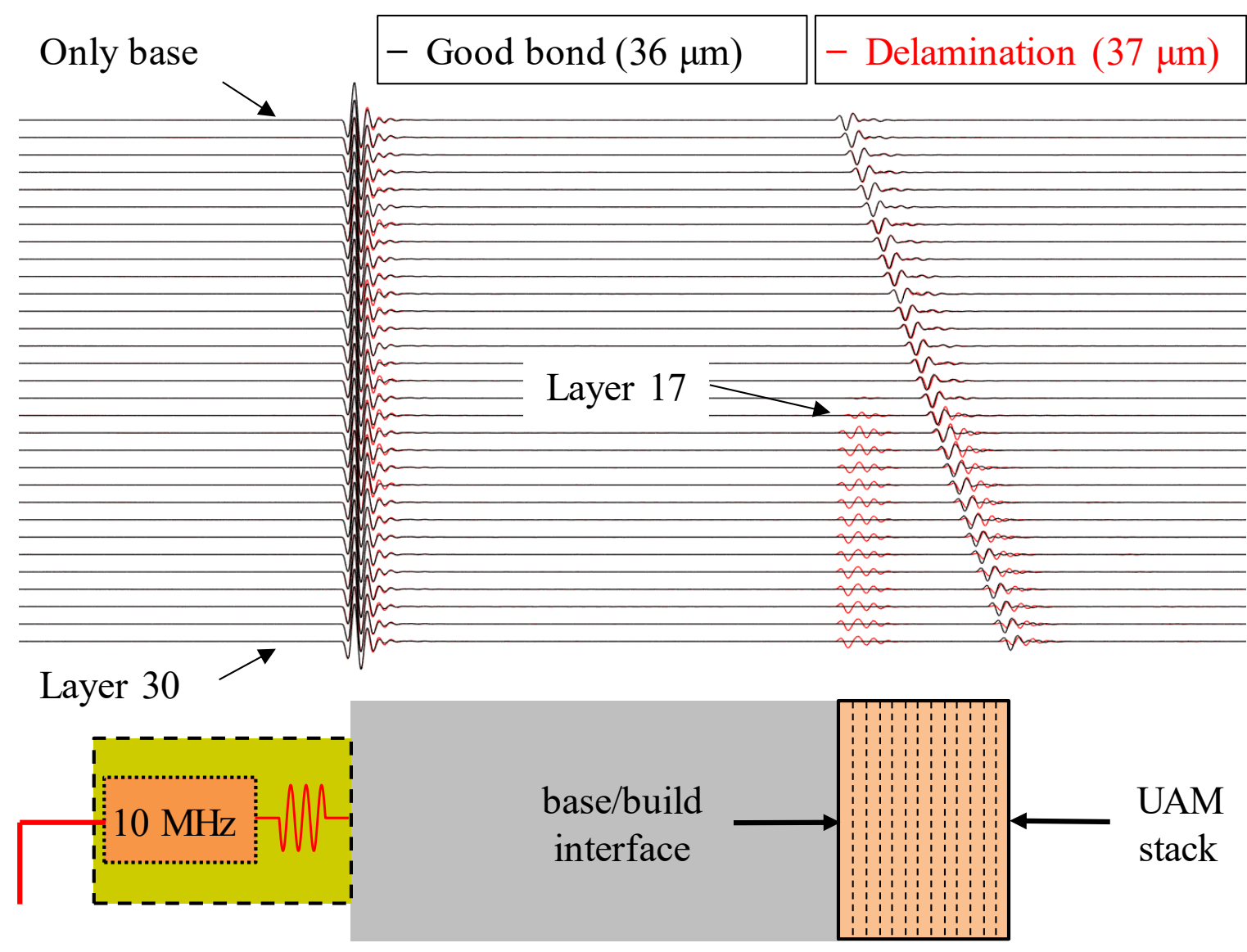

Figure 2: In-situ monitoring after bonding each UAM layer for two components of varying quality. The reverberation from the oil buffer was cut out from the signals, so that the features of interest can be better represented. 


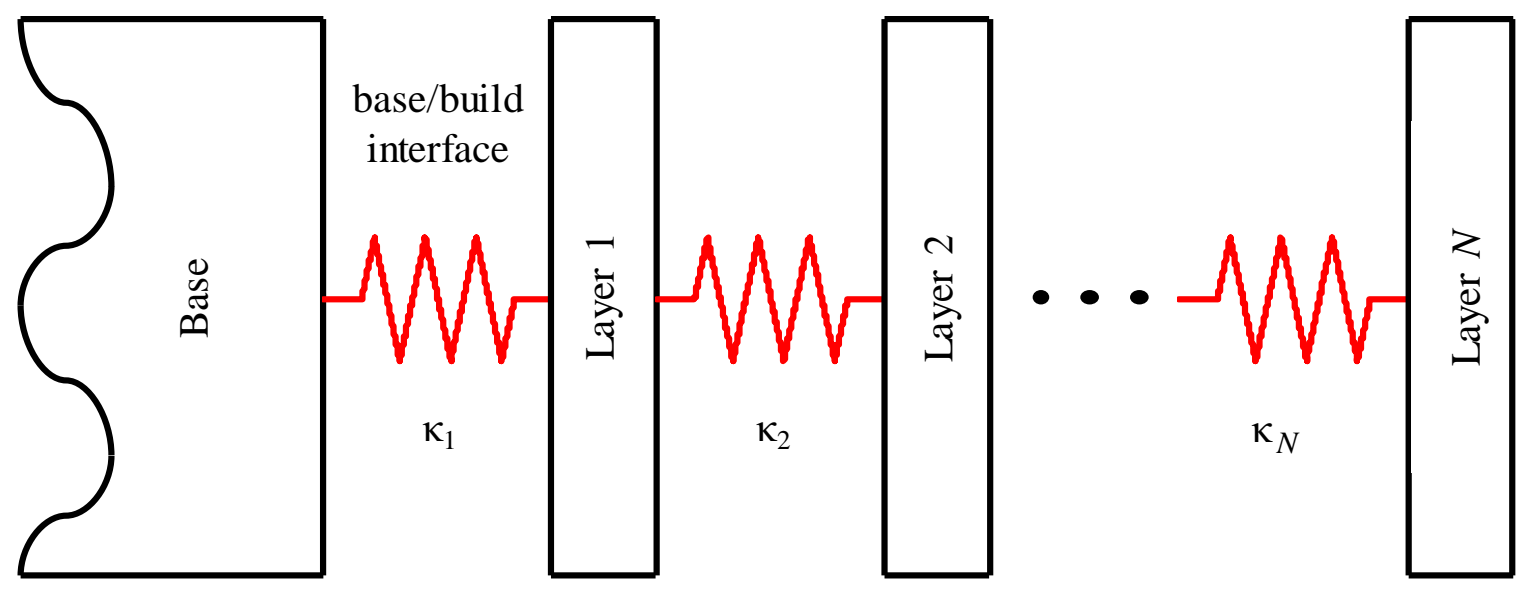

Figure 3: Schematic of UAM interfaces as finite stiffness springs [18-19]. 
a)

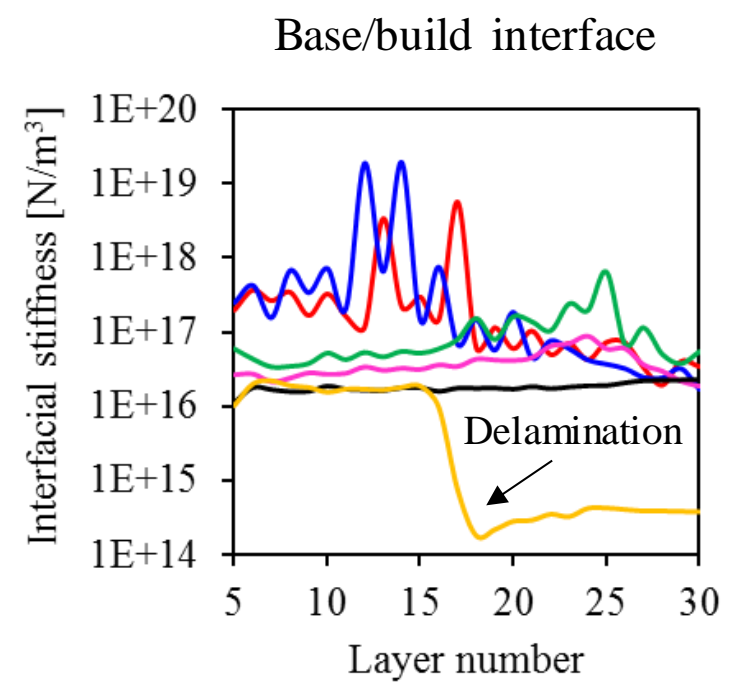

$-30 \mu \mathrm{m}-31 \mu \mathrm{m}-32 \mu \mathrm{m}$

$-34 \mu \mathrm{m}-36 \mu \mathrm{m}-37 \mu \mathrm{m}$ b)

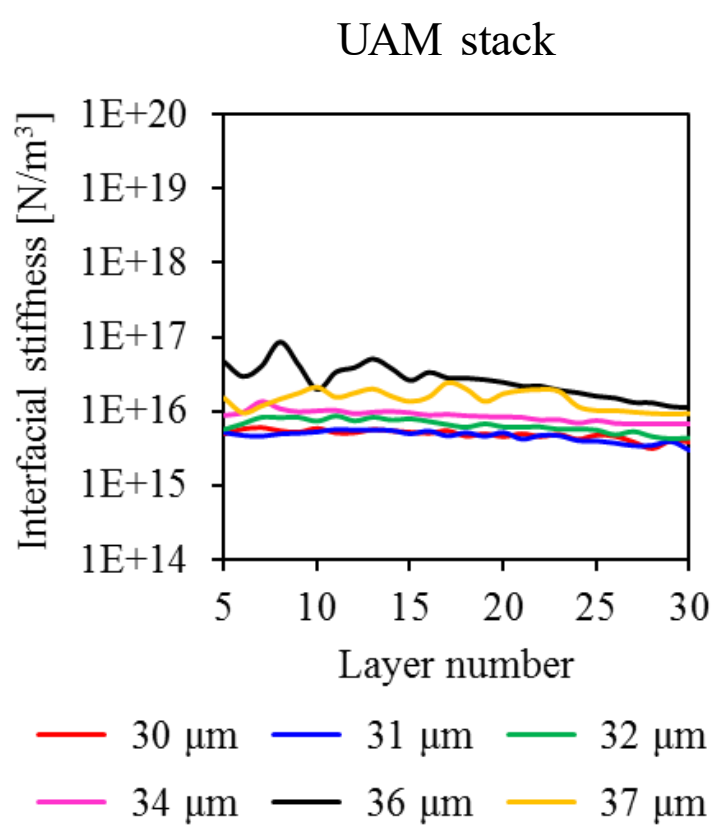

Figure 4: Interfacial stiffness values of components with varying quality a) base/build interface, b) average of UAM stack. 


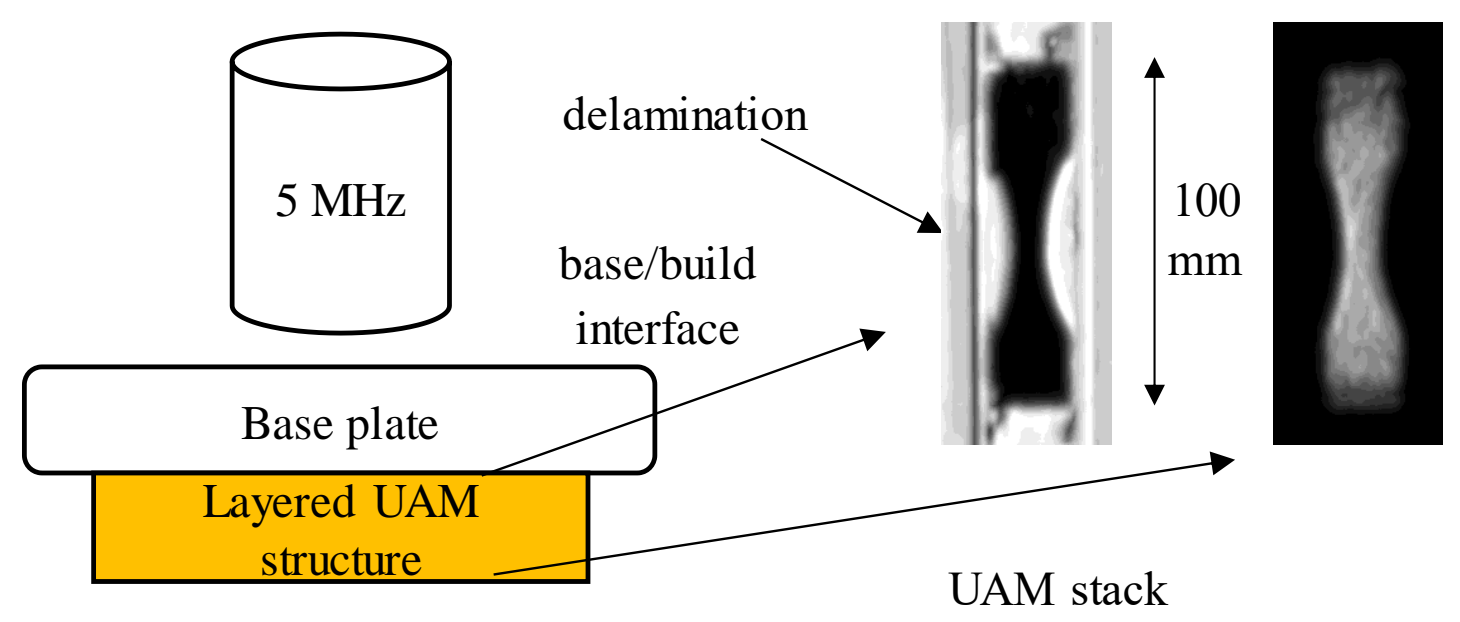

Figure 5: Acoustic microscopy gated to generate images at the base build interface (reflection image) and the UAM stack (transmission image). 

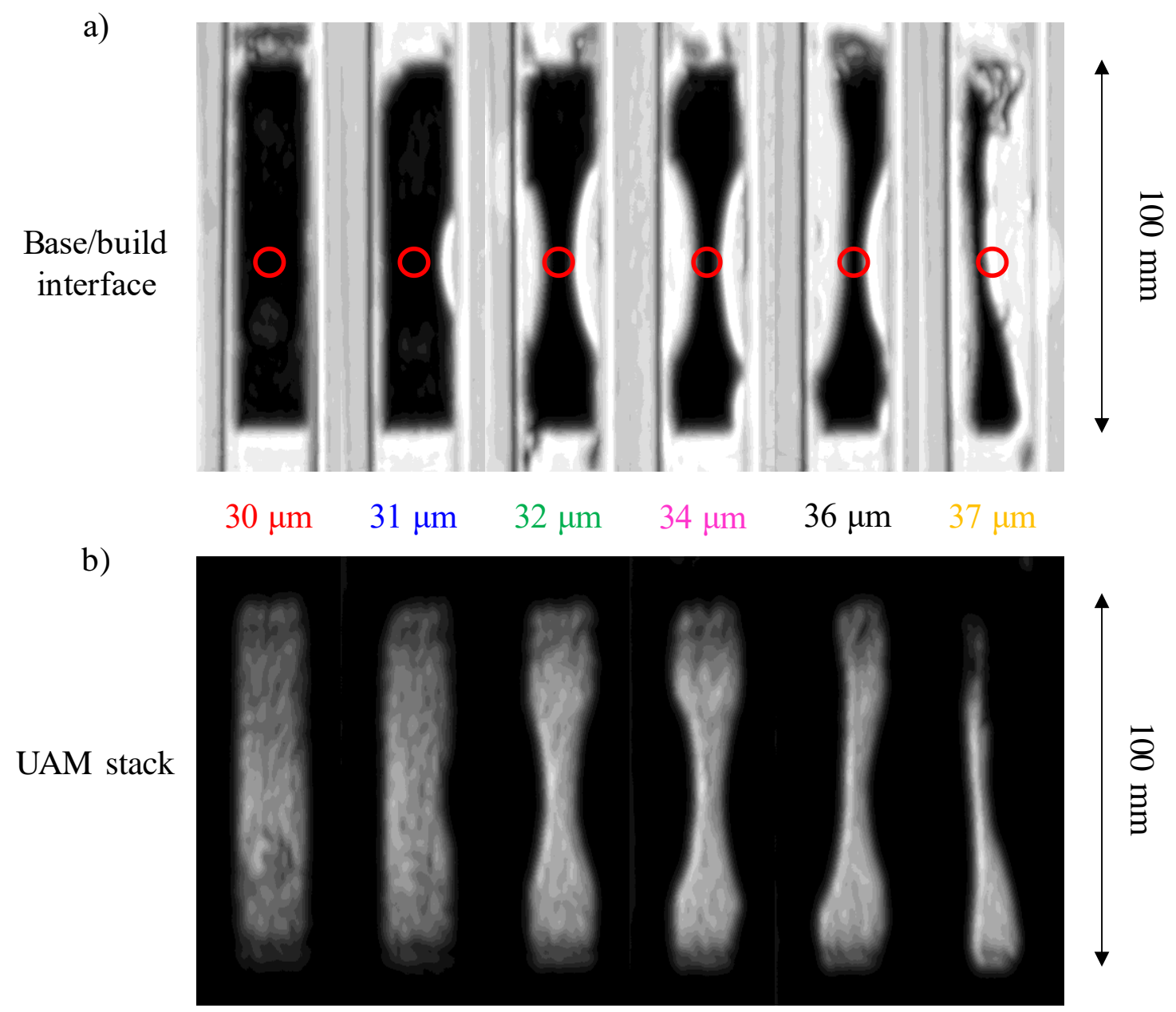

Figure 6: Acoustic microscopy of UAM components at a) base/build interface (reflection image) and b) The top of UAM stack (transmission image). In the reflection image, black indicates a good bond while in the transmission image white indicates a good bond. 
a)

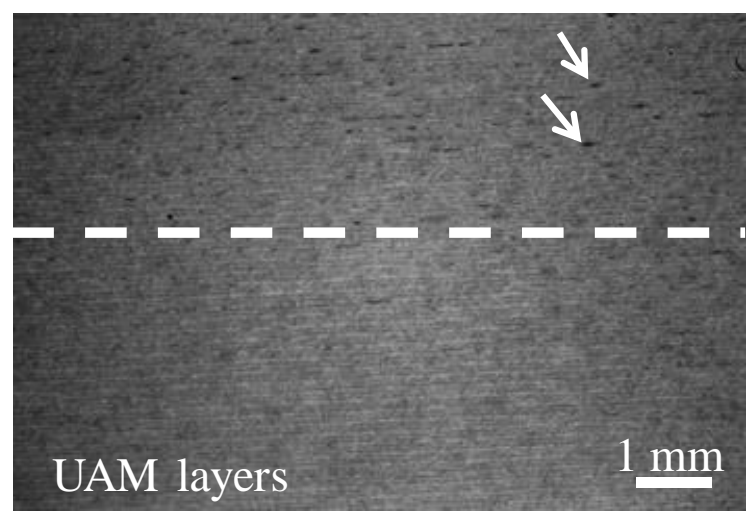

c)

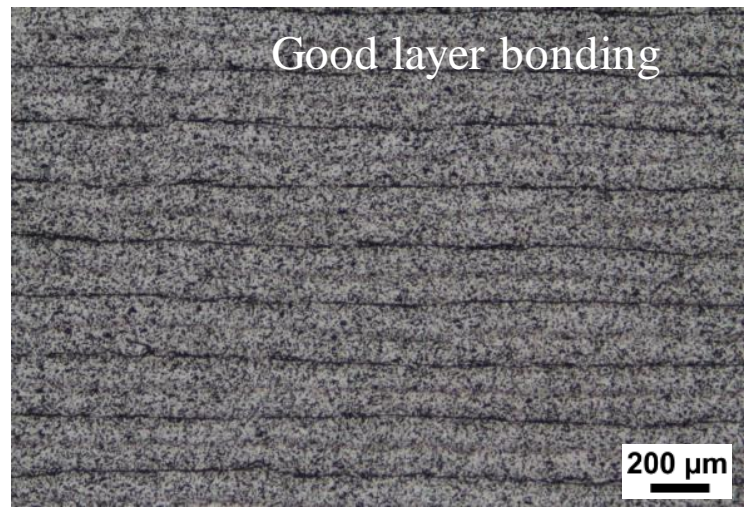

b)

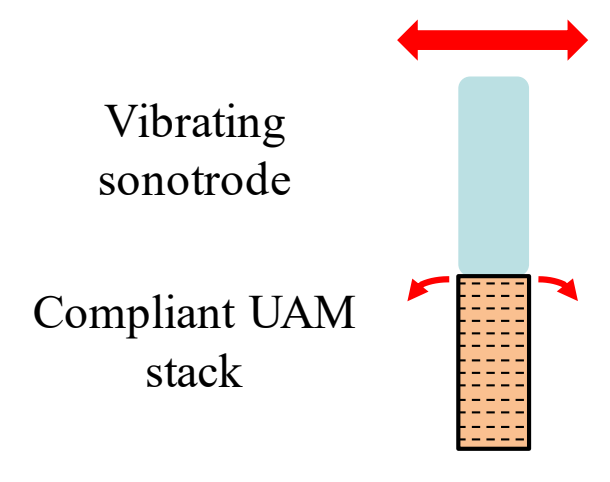

d)

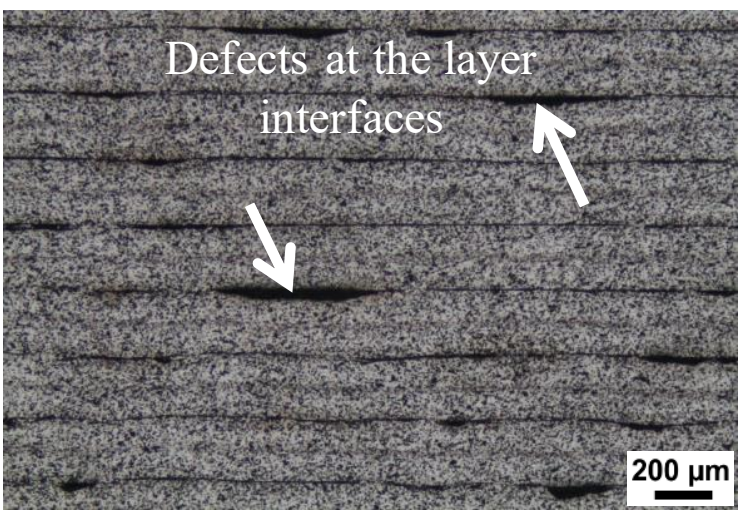

Figure 7 (a) Low-magnification optical micrograph of a $11.5 \mathrm{~mm}$ height UAM sample. In the first $7.5 \mathrm{~mm}$ from the bottom, the sample showed good layer bonding (b). In the top $4 \mathrm{~mm}$, several Type-1b defects (marked by arrows) were seen at the layer interfaces (c). 
a)

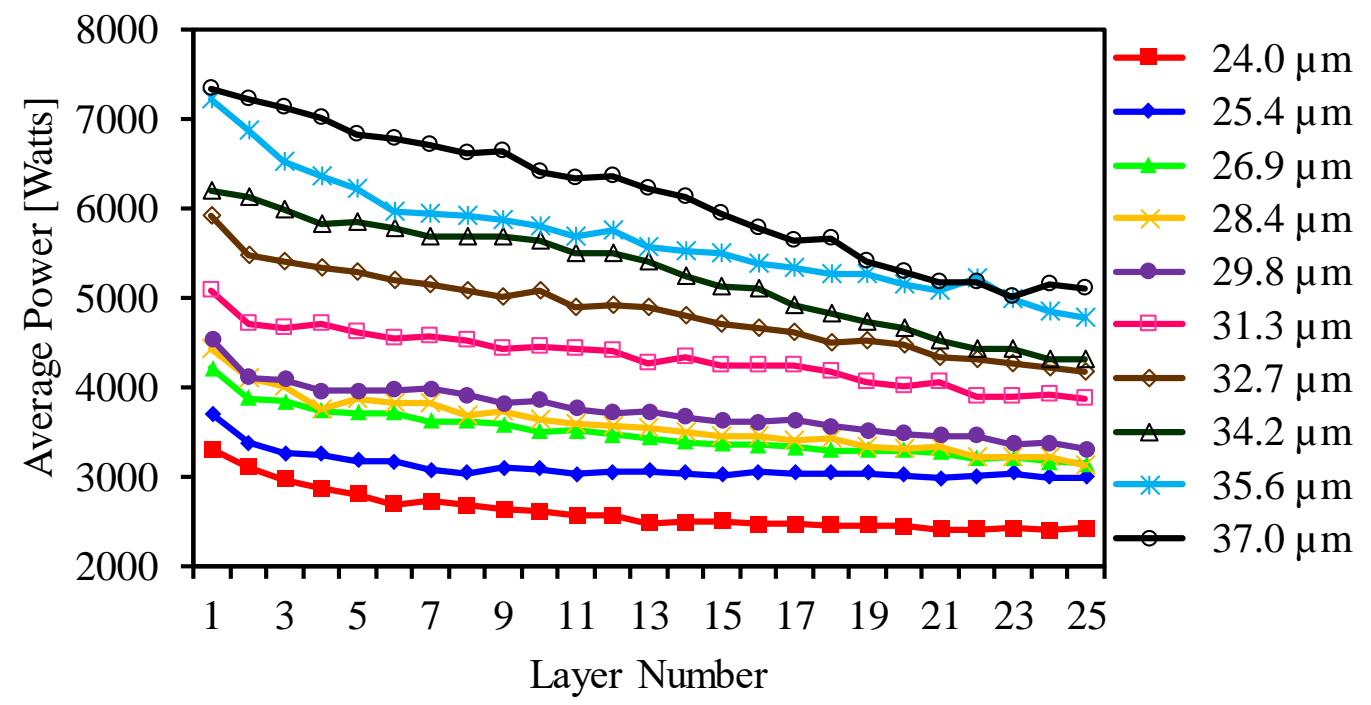

b)

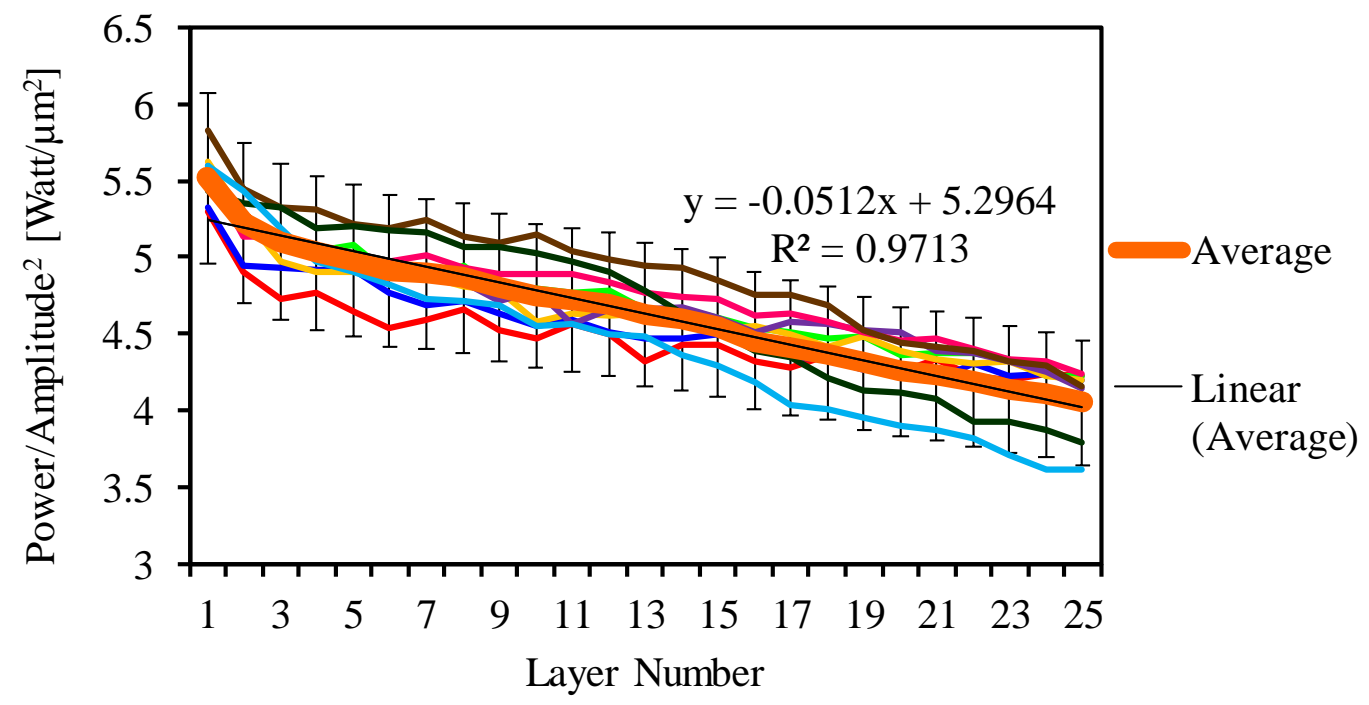

Figure 8 a) Change in average weld power with layer height for varying vibration amplitudes b) Normalized power. 


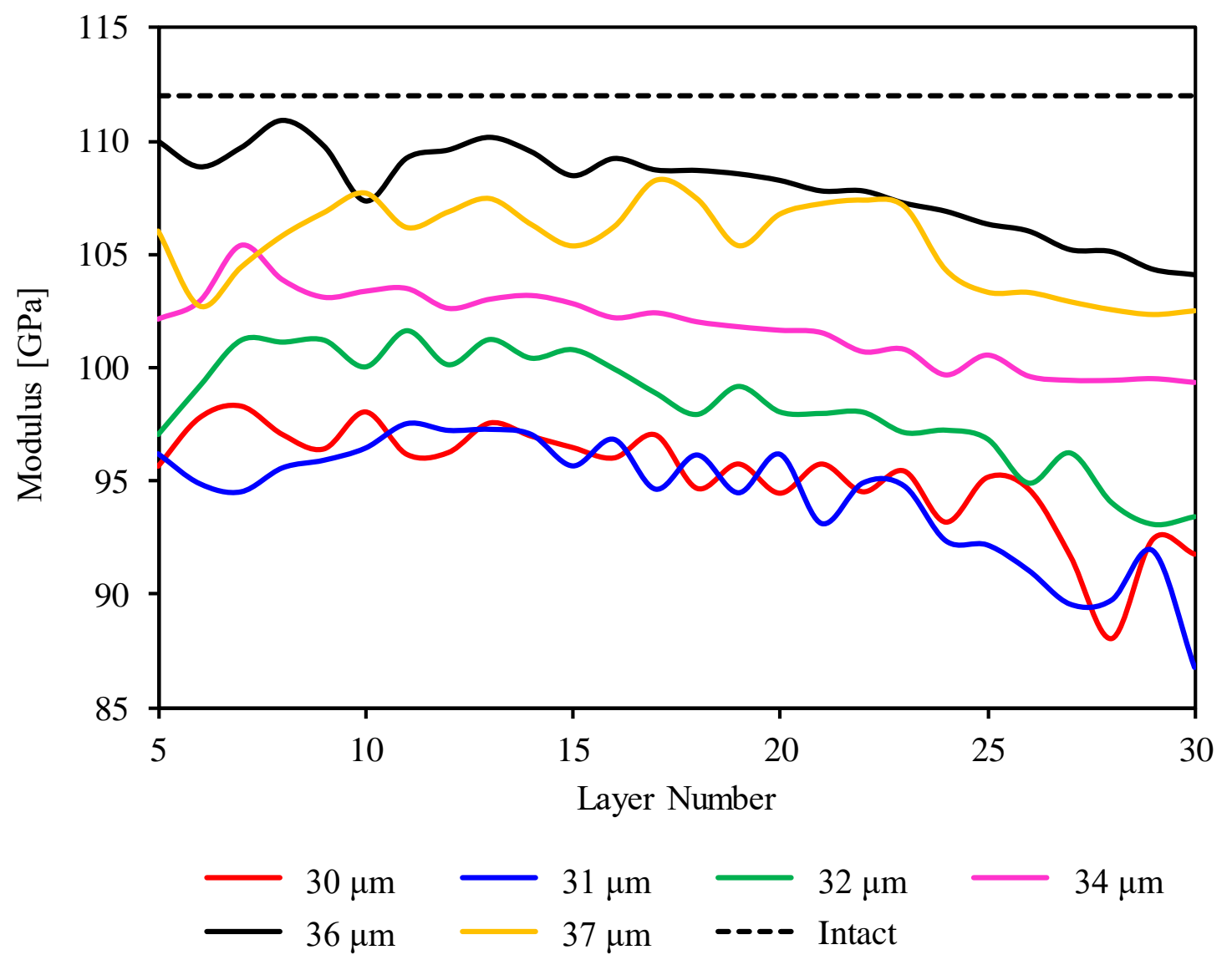

Figure 9: Change in UAM stack modulus with layer height and vibration amplitude calculated by a model-based inversion of in-situ monitoring NDE signals. 


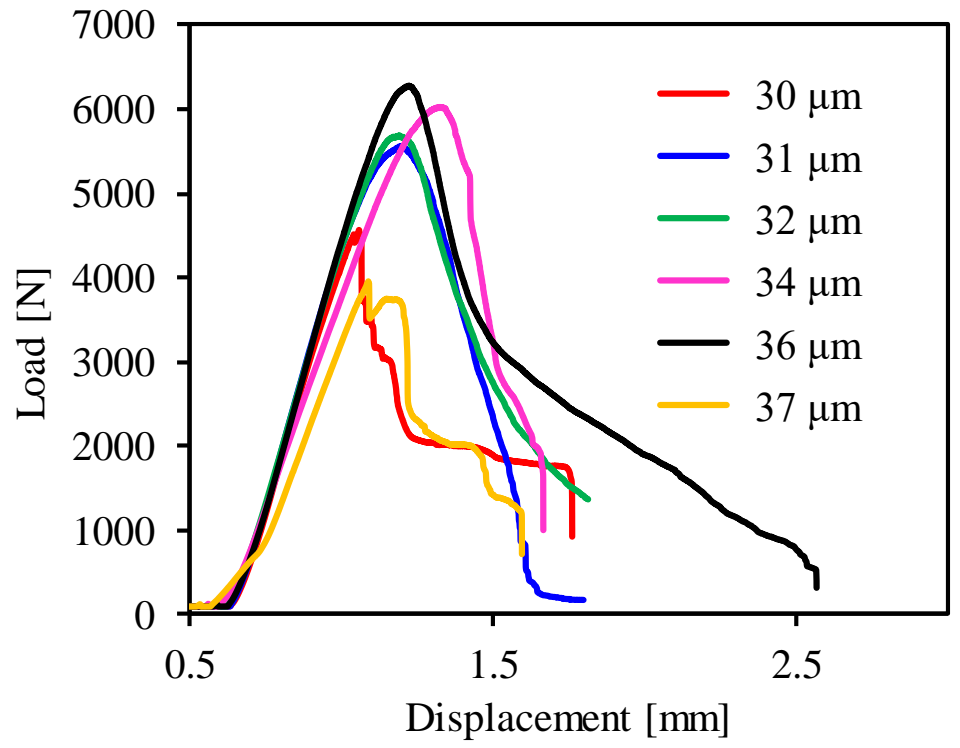

Figure 10: Push-pin test results for various vibration amplitudes. 


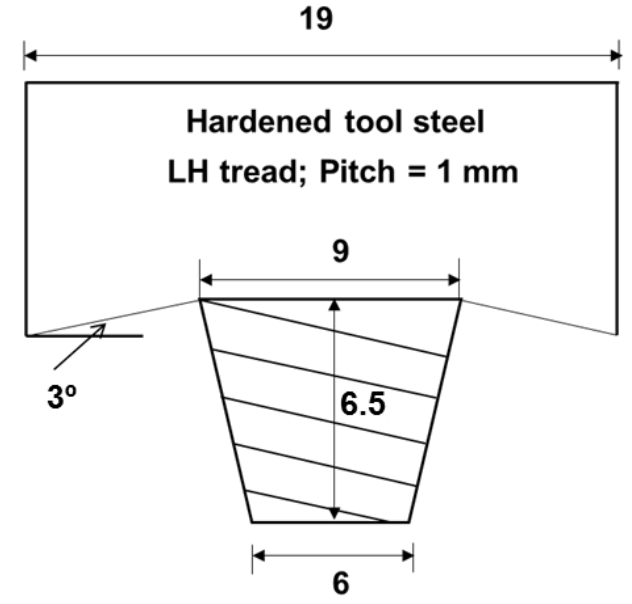

FSP tool

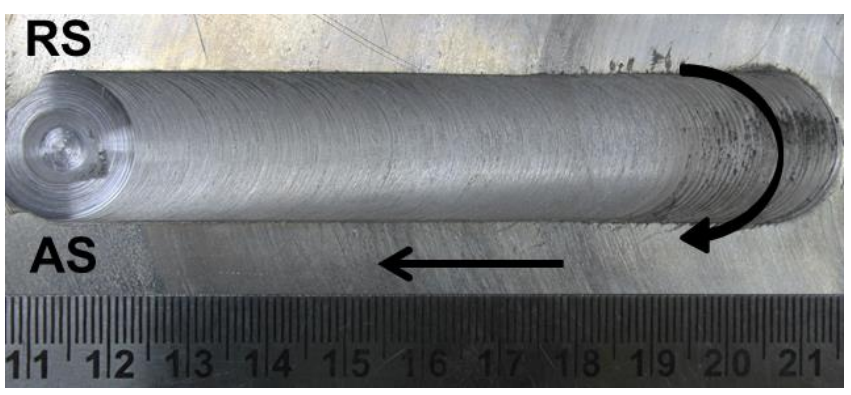

FSPed sample

Figure 11: Schematic of FSP tool and a typical FSPed sample (top view). Arrows show the directions of tool rotation and travel. AS and RS denote the advancing and retreating sides of the processed region. 
a)

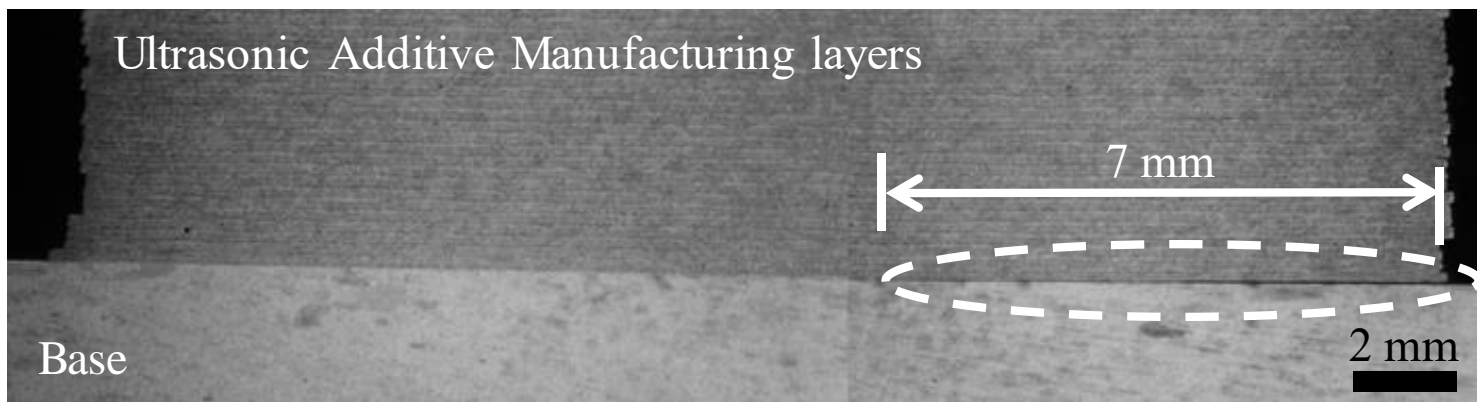

b)

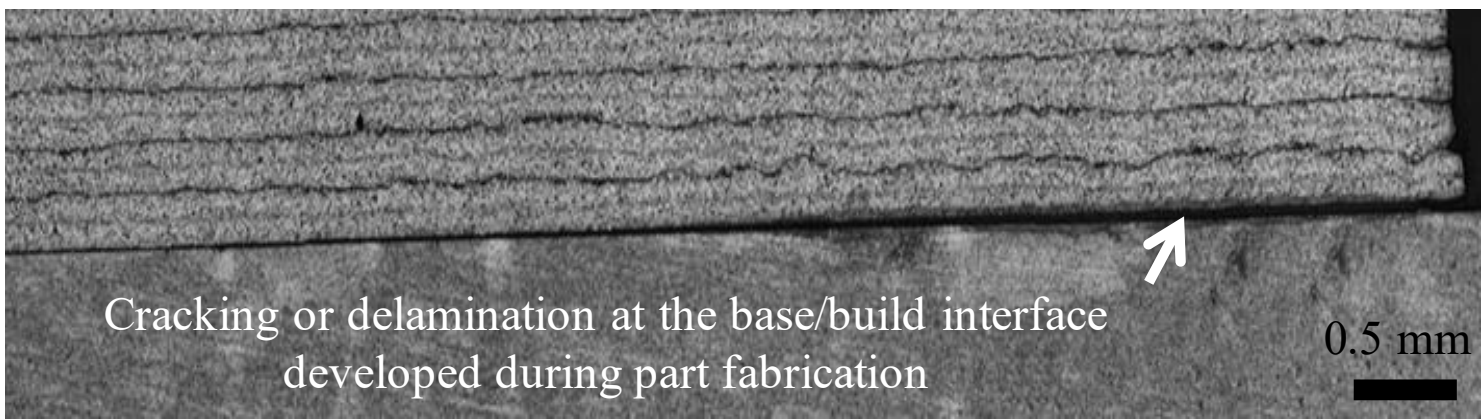

Figure 12: (a) Optical micrograph of a UAM build. Encircled region marks a crack at the base/build interface. The crack is shown at a higher magnification in (b). 


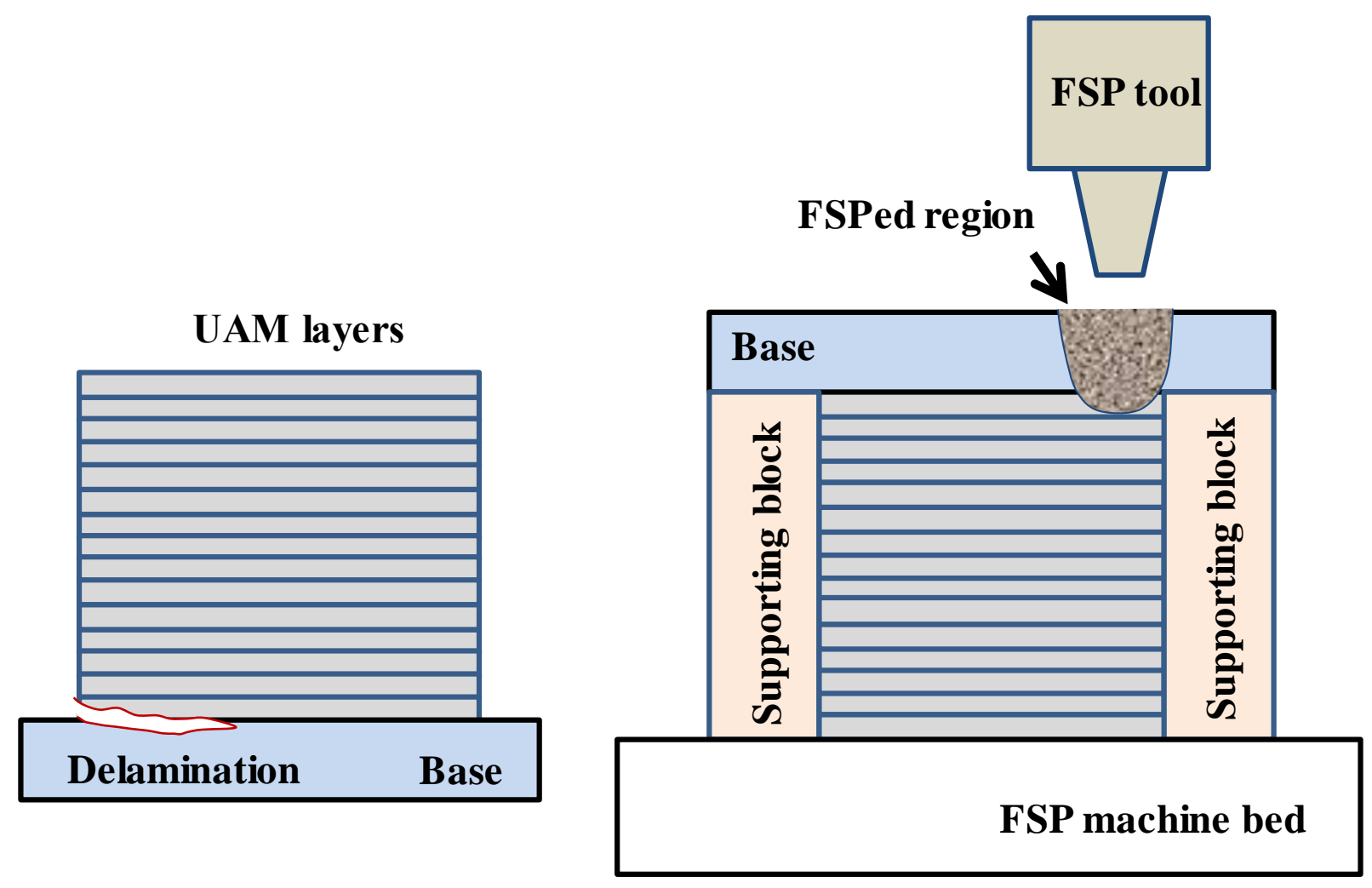

Figure 13: Schematic illustration of the use of FSP for healing base/build interface delamination (Type-1a defects). 

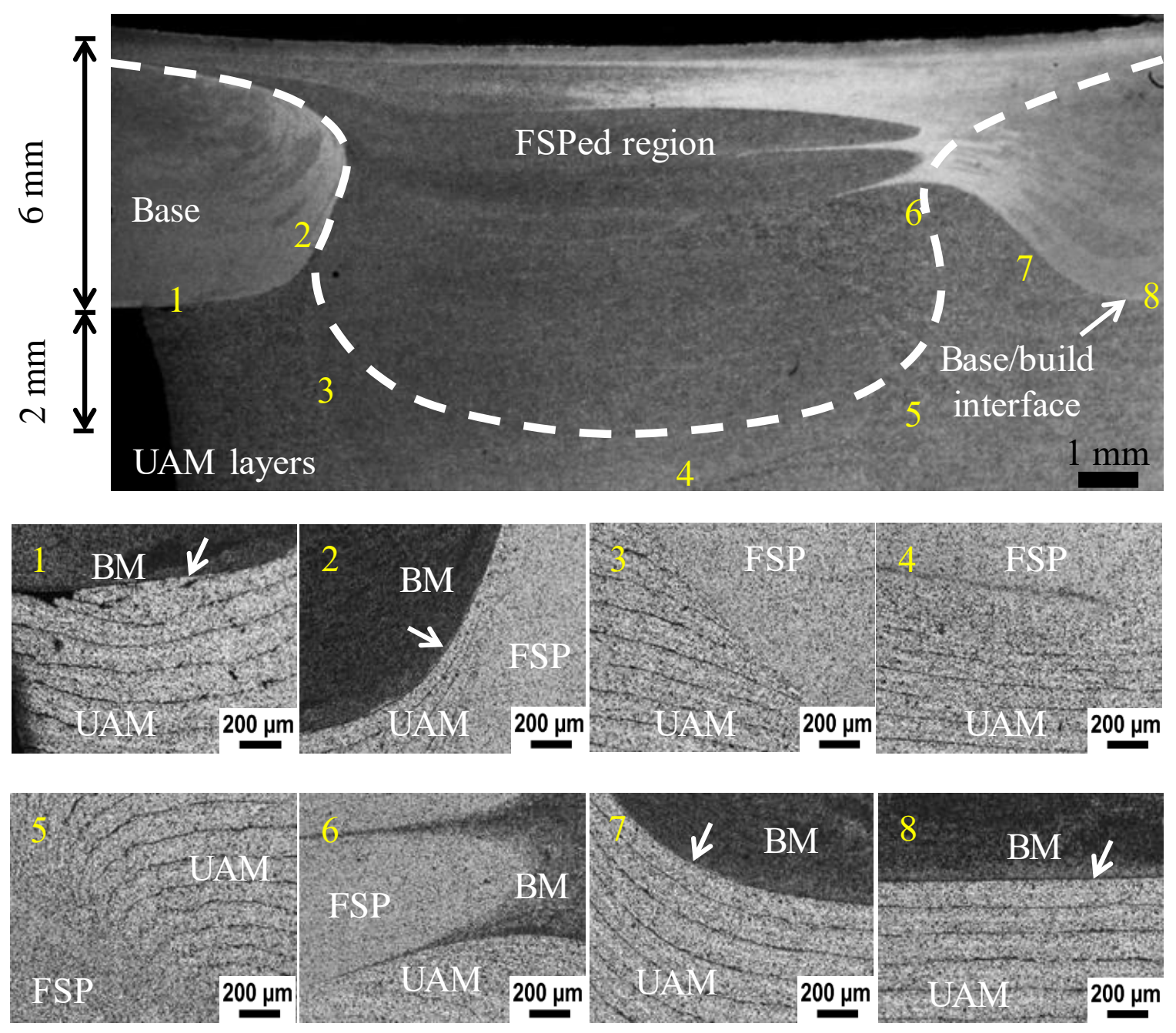

Figure 14: Optical micrographs a UAM sample FSPed for repair of a base/build interface (Type1a) defect. The crack is completely healed by FSP. 
Delamination healed

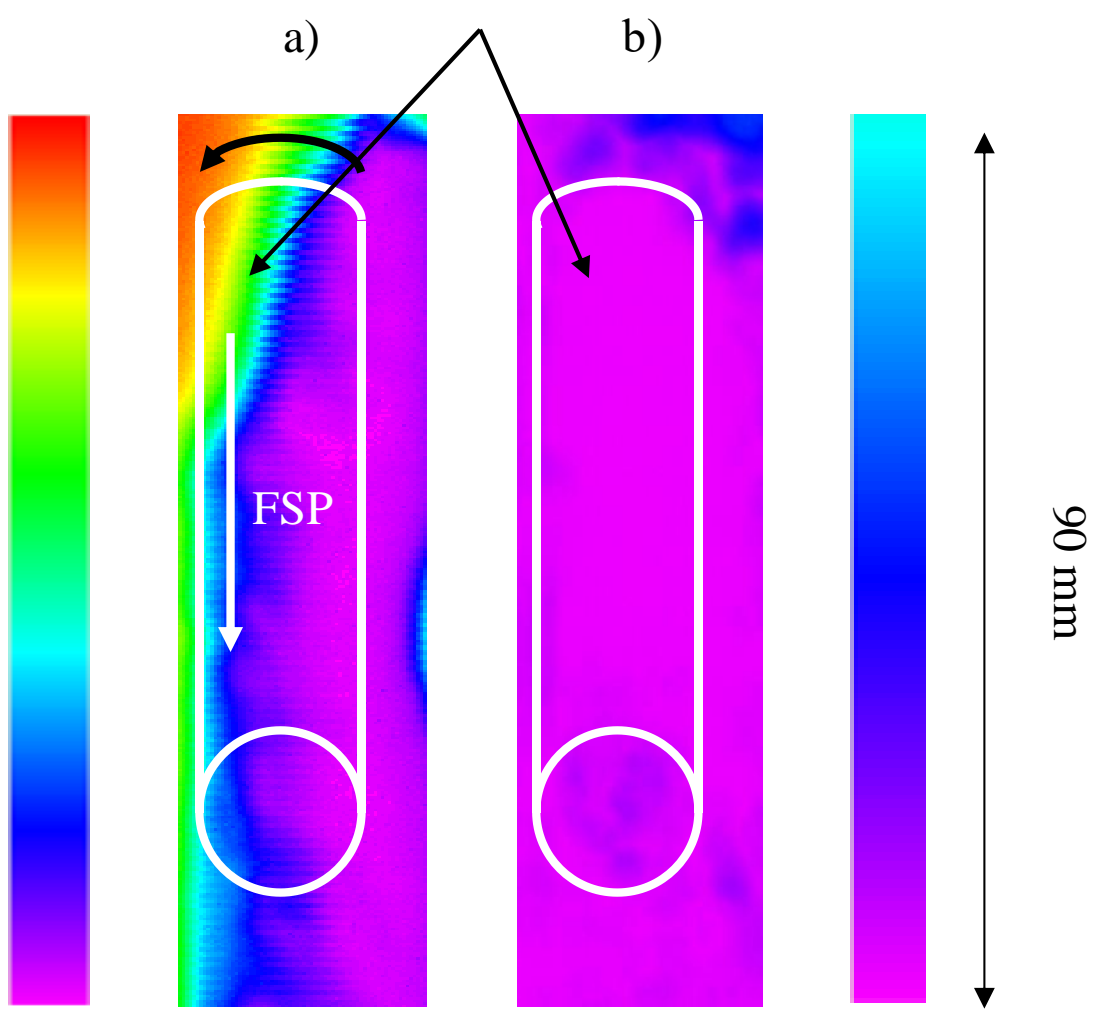

Figure 15: Acoustic microscopy images: (a) as-built, (b) after FSP. The color scale of the two images is different with a higher value representing a larger reflection and thus a delamination. 

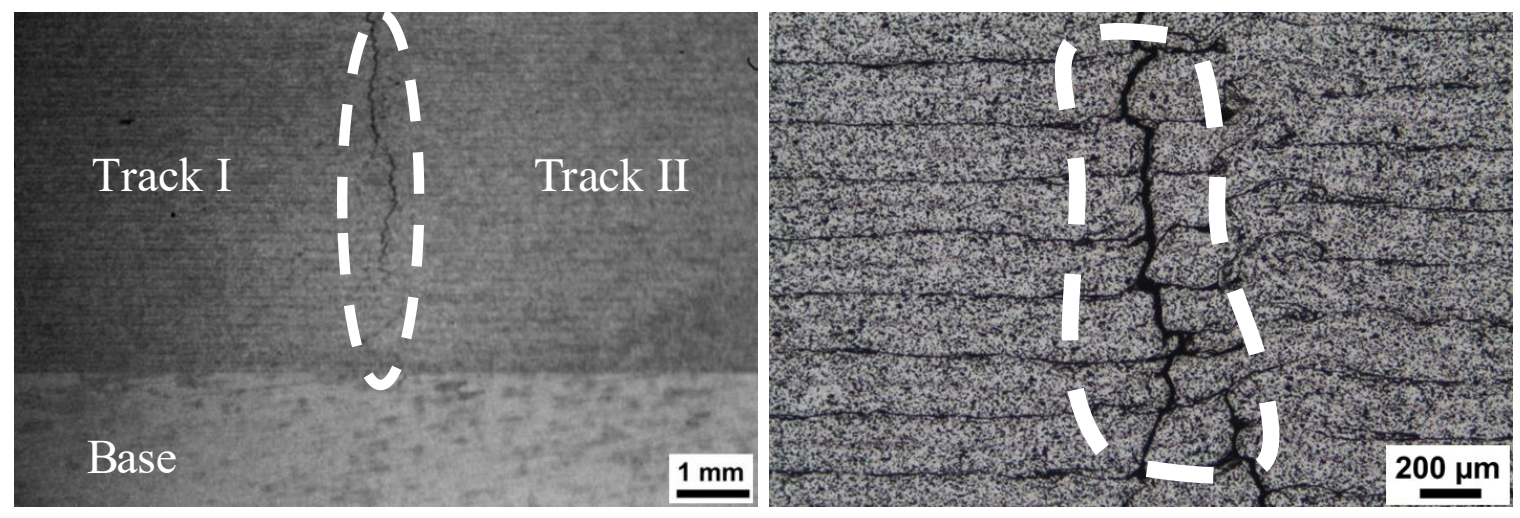

Figure 16: Inter-track defects typically found in UAM components. 


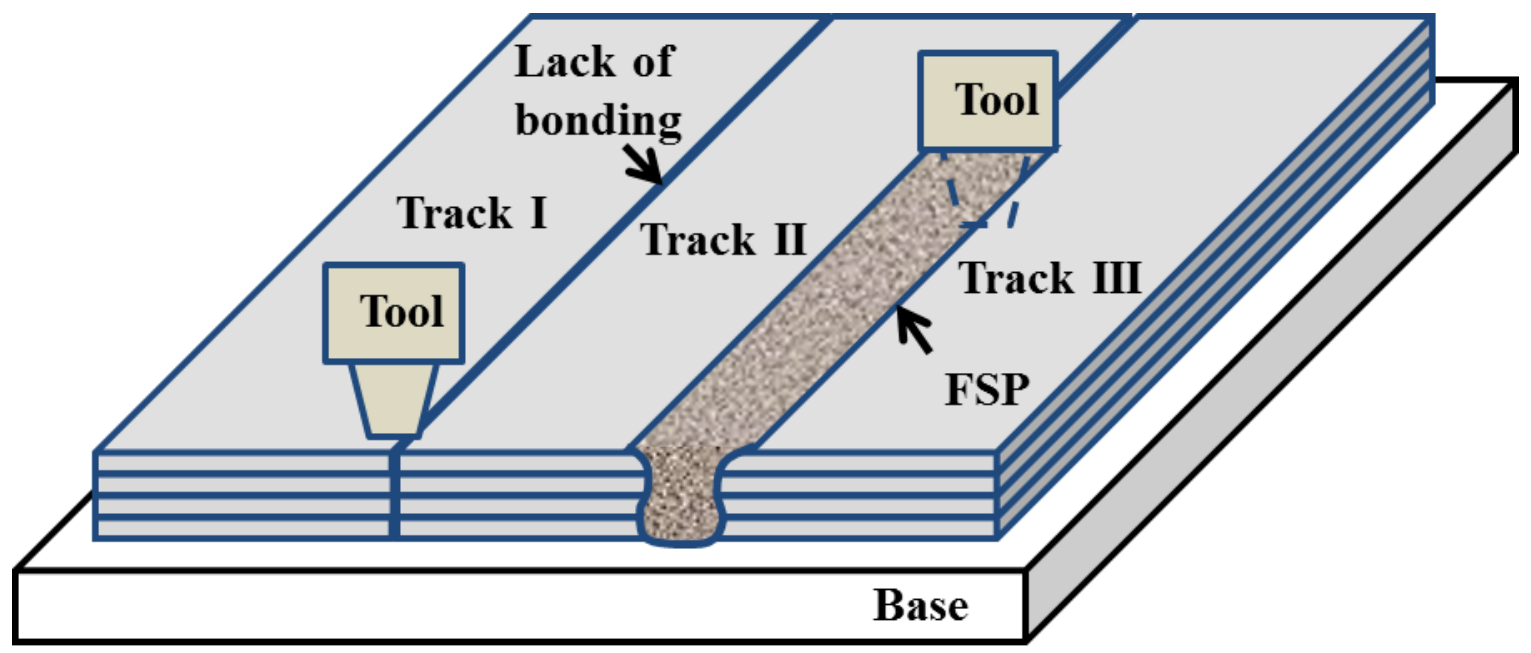

Figure 17: Schematic illustration of the use of FSP for repair of Type-2 defects in UAM parts. 

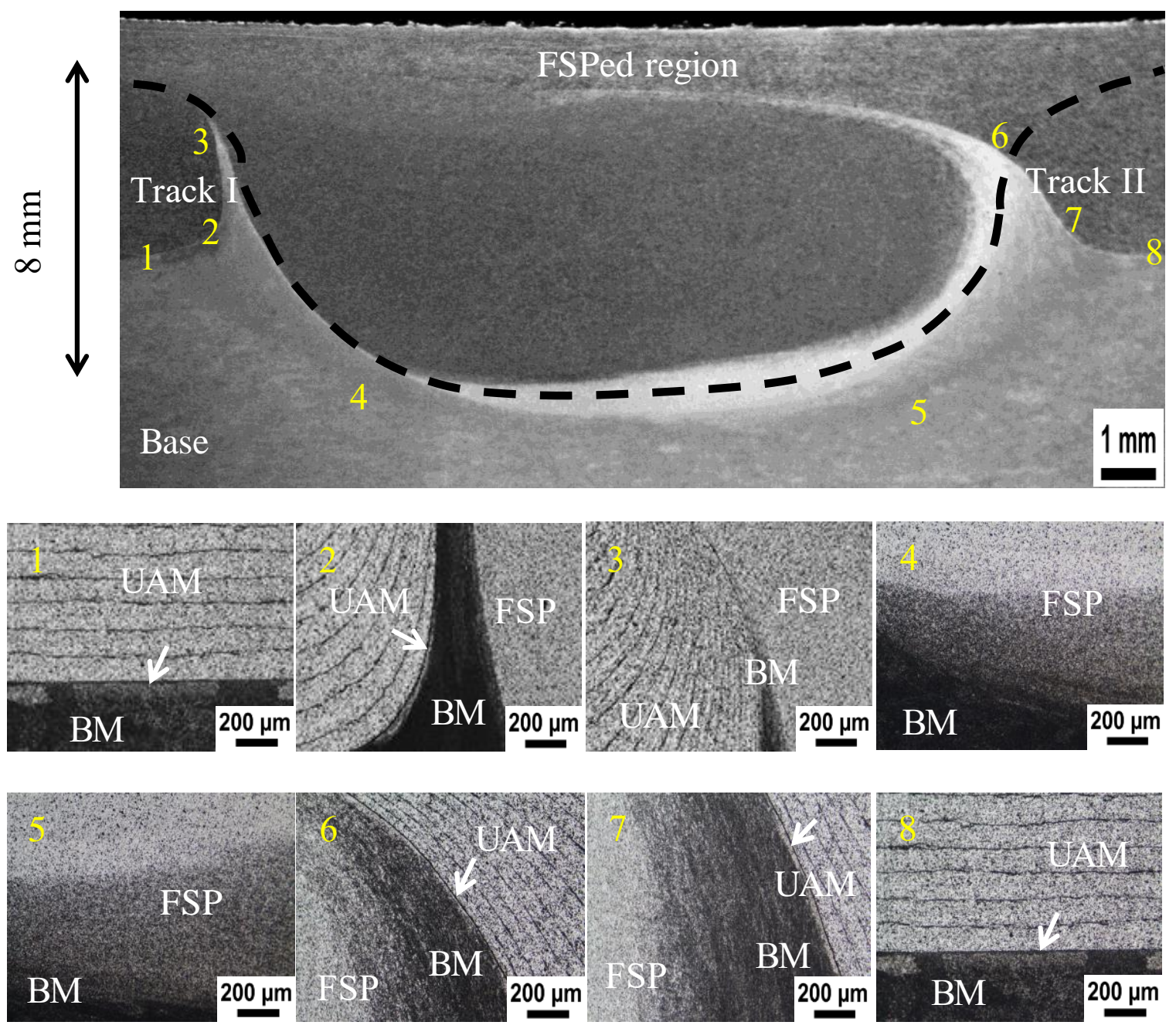

Figure 18: Optical micrographs of a UAM sample FSPed for repair of a Type-2 defect. The defect is completely healed by FSP. 


\section{Appendix A}

\section{Bond quality inversion of UAM components using in-situ ultrasonic NDE}

A method for a model-based bond quality inversion has been presented in Nadimpalli et al. [19]. Due to the change in experimental setup, we discuss the methodology here briefly. Figure A.1 shows the typical signals captured during in-situ monitoring using a $10 \mathrm{MHz}$ ultrasonic delay line transducer. One of the two signals selected is the same as Figure 2 while the other one is a lower quality component. These two components The primary difference between the current setup and the one discussed in Nadimpalli et al. [19] is the presence of a coupling oil with an immersion mode instead of a contact mode measurement. The contact measurement is not consistent due to the vibration of the base structure which might cause a variation in the coupling conditions.

To compare signals from various layers and components, the signal is phase shifted and normalized so that the front surface signals are identical. The two distinct features of interest, base/build delamination and the signal from top of the stack are gated as shown. The base/build interface gate is fixed in time while the stack gate moves with changing layer number. Both the base/build and stack gates are chosen with smallest possible overlap so that the interference effects between the two signals are minimized during bond quality evaluation. Using the signal from the base as a reference, the phase delay and attenuation are calculated by the means of a Fourier transformation. To estimate the phase velocity $\left(c_{\mathrm{p}}\right)$, the average thickness of each component was measured with digital calipers and the layer thickness was calculated. The attenuation coefficient $(\alpha)$ is calculated after diffraction correction. 


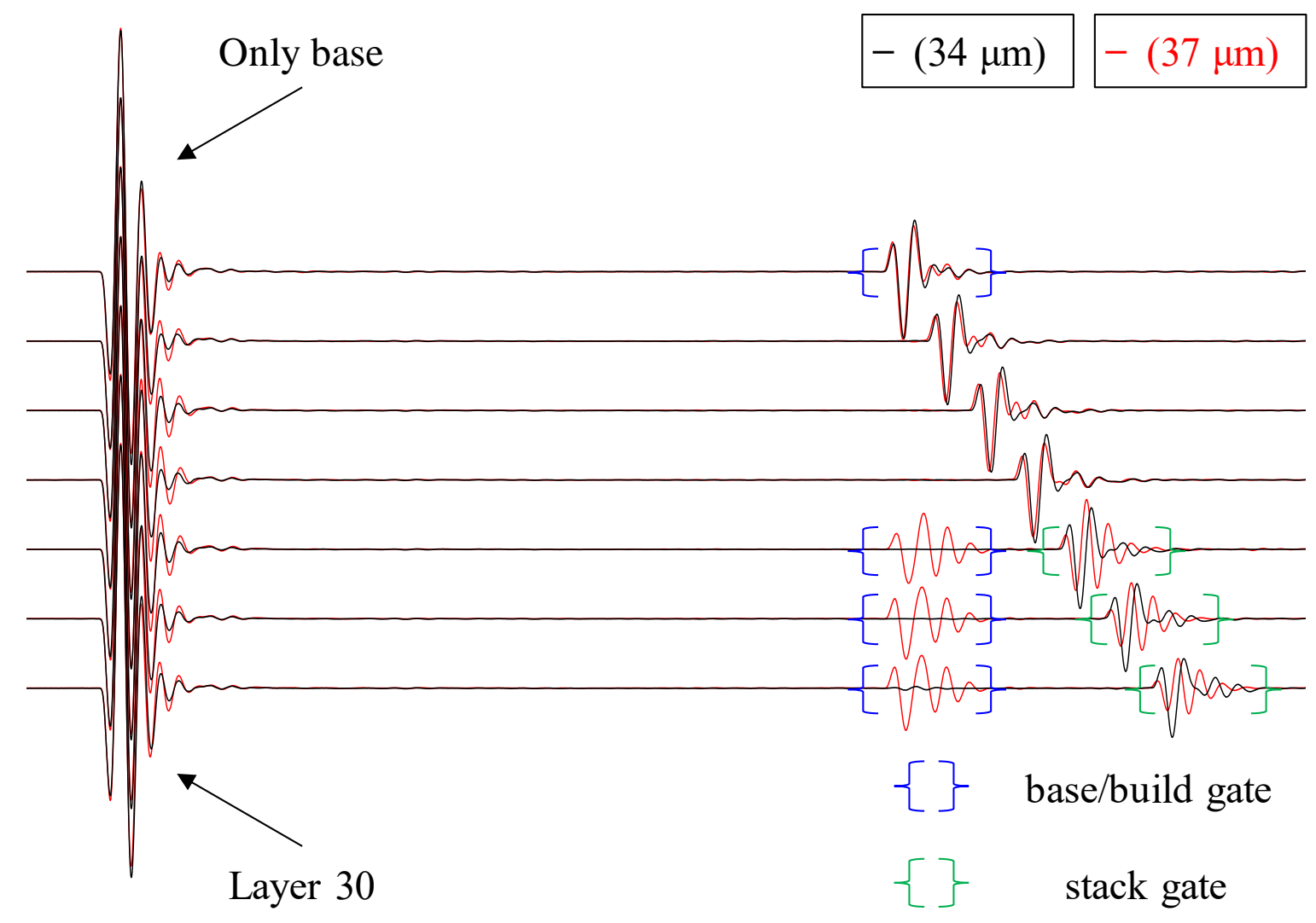

Figure A.1: Ultrasonic signals of UAM components from in-situ monitoring.

Under the influence of high frequency ultrasonic vibration, the modulus of the UAM stack is better represented with a complex dynamic modulus $\tilde{C}_{\text {stack }}$ having both real and imaginary components that represent the storage and loss moduli, respectively. After some tedious algebra, the complex stack impedance can be estimated as

$\tilde{C}_{\text {stack }}=\rho c_{\mathrm{p}}^{2}(1+2 i \psi)$.

where $\psi$ is a dimensionless real quantity representing the ratio between the imaginary $\left(c_{\mathrm{i}}\right)$ and real $\left(c_{\mathrm{r}}\right)$ parts of the phase velocity. It can also be related to experimentally measured attenuation $(\alpha)$ and phase velocity $\left(c_{\mathrm{p}}\right)$ as 


$$
\frac{\alpha c_{\mathrm{p}}}{\omega}=\frac{c_{\mathrm{i}}}{c_{\mathrm{r}}}=\psi
$$

Thus, the dynamic modulus of the UAM stack can be estimated from experimentally measured phase velocity and attenuation. The modulus of the UAM stack can be thought of as the combination of the set of imperfectly bonded layers one on top of the other. Hence, for a component of $N$ layers with one base/build interface the modulus can be estimated as

$$
\frac{N}{\tilde{C}_{\text {stack }}}=\frac{1}{\eta_{1} C_{\text {layer }}}+\frac{N-1}{\eta C_{\text {layer }}}+\frac{N}{C_{\text {layer }}}
$$

Where $\eta_{1}$ is the base/build interfacial stiffness coefficient and $\eta$ is the stack stiffness coefficient. For a large enough number of layers $(N>5)$ the stack stiffness coefficient can be estimated as

$$
\eta \approx \frac{\tilde{C}_{\text {stack }}}{C_{\text {layer }}-\tilde{C}_{\text {stack }}}
$$

This forms the first estimate of $\eta$, from which we can calculate the dispersive stack impedance ( $\left.Z_{\text {stack }}\right)$ and thus the base/build stiffness coefficient $\eta_{1}$. In the case of an Aluminum 6061 base and Al6061 UAM stack, the displacement reflection coefficient would be

$$
R=\frac{\frac{Z_{0}-Z_{\text {stack }}}{Z_{0}+Z_{\text {stack }}}+\frac{i \omega Z_{\mathrm{p}}}{2 \kappa_{1}}}{1+\frac{i \omega Z_{\mathrm{p}}}{2 \kappa_{1}}}
$$

$Z_{0}$ and $Z_{\text {stack }}$ are the acoustic impedances of the base and the stack, respectively, $\omega$ is the angular frequency, $\kappa_{1}$ is the normal interfacial stiffness, and $Z_{\mathrm{p}}$ is a combination of the two acoustic impedances 
$Z_{\mathrm{p}}=\frac{2 Z_{0} Z_{\text {stack }}}{Z_{0}+Z_{\text {stack }}}$.

The reflection coefficient can also be obtained as a ratio of the Fourier transform of the base/build gate signal to that of the reference. The corresponding complex interfacial stiffness estimate is

$\kappa_{1}=\frac{i \omega Z_{\mathrm{p}}}{2} \frac{1-R}{R-R_{0}}$,

where $R_{0}$ is the reflection coefficient from the perfectly bounded base/build interface,

$R_{0}=\frac{Z_{0}-Z_{\text {stack }}}{Z_{0}+Z_{\text {stack }}}$.

Equation A.7 is the first estimate of $\kappa_{1}$ which can be used to recalculate the stack interfacial stiffness $\kappa$ according to Equation A,3. The process is iteratively performed until it reaches convergence which usually takes 3-4 cycles of the loop shown below in Figure A.2.

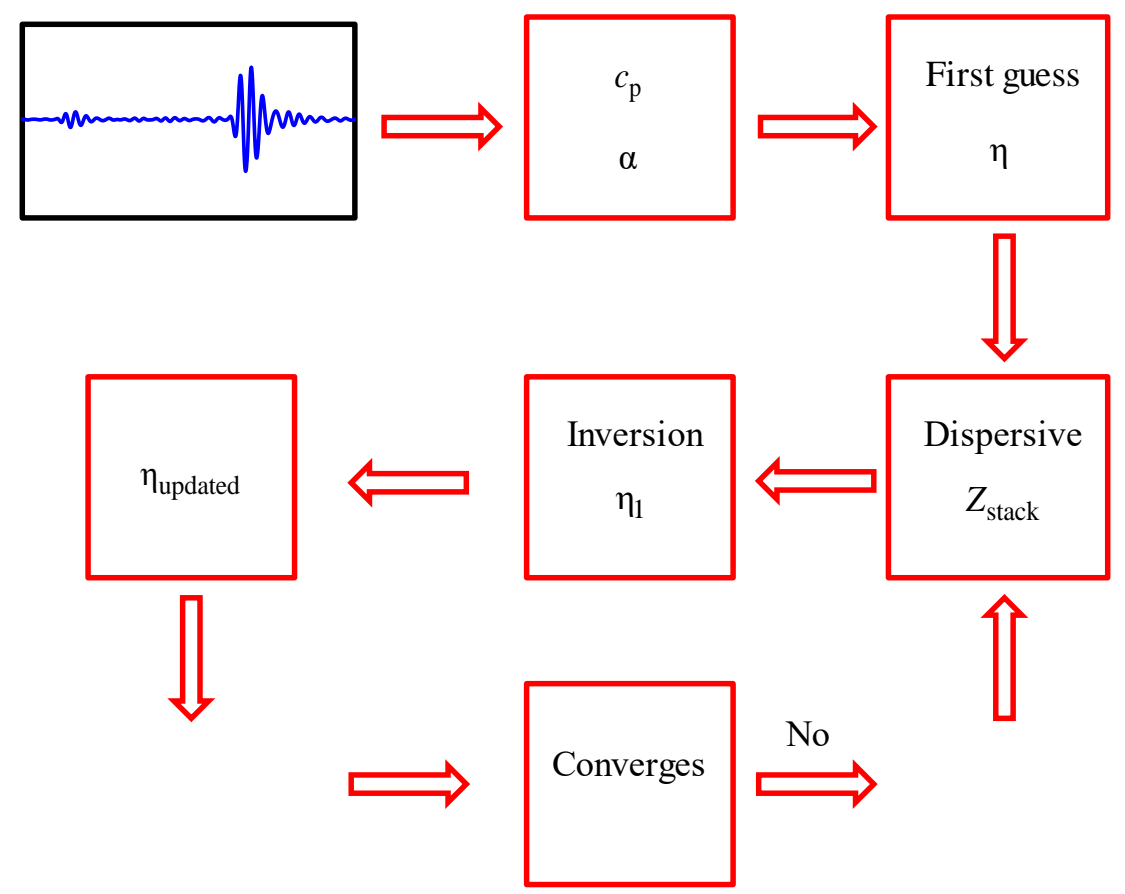

Figure A.2: Schematic of inversion model to calculate $\eta_{1}, \eta$. 


\section{Appendix B}

\section{Calibration of UAM vibration amplitude}

The UAM process utilizes a $20 \mathrm{kHz}$ transducer to vibrate the sonotrode during bonding. The vibration amplitudes range form $20-50 \mu \mathrm{m}$ and can be measured using a laser vibrometer. It is essential to calibrate the UAM system before welding to ensure that the vibration amplitude setting $[0-100 \%]$ corresponds to the intended vibration amplitude. A laser vibrometer was used to measure the velocity of the sonotrode as shown in Figure B.1 below.

a)

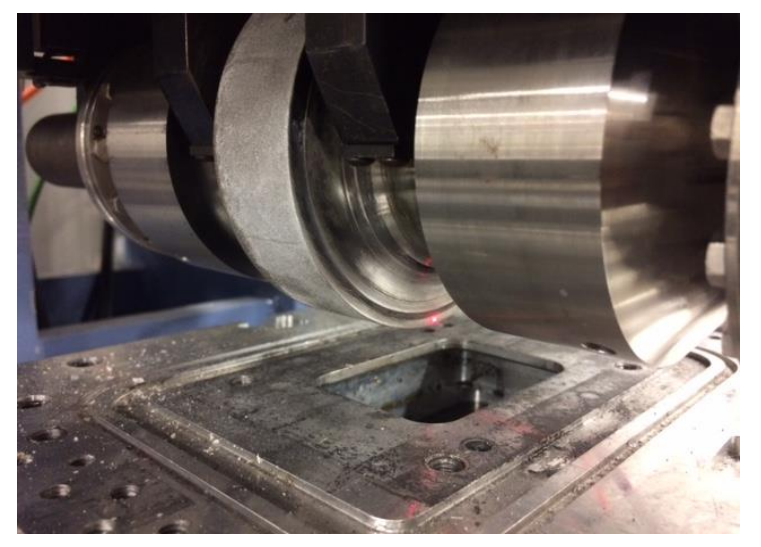

b)

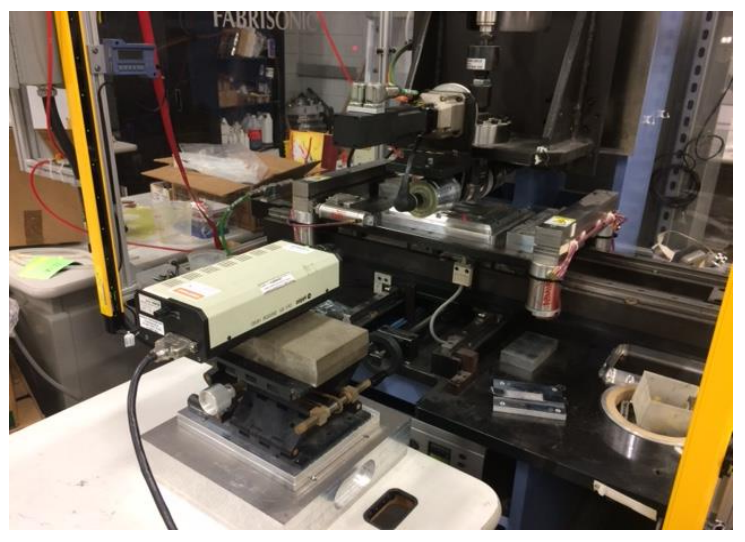

Figure B.1: a) Laser interferometer focused on the UAM sonotrode b) Laser vibrometer setup outside a Fabrisonic R200 UAM system for noncontact measurement.

The harmonic signal obtained during vibration in free air at $70 \%$ amplitude setting is shown in Figure B.2 below. We can use this signal to calculate the frequency and amplitude of vibration based on the sensitivity of the vibrometer. The frequency of vibration is close to 20 $\mathrm{kHz}$ and remained constant throughout testing. The vibration amplitude was changed from 20$100 \%$ setting and the physical amplitude was calculated from the velocity profiles. The R200 system and the R7200 system were calibrated in 2012 at a sensitivity of $5000 \mathrm{~mm} / \mathrm{s} / \mathrm{V}$. In 2015, we calibrated the same R200 system. The results of the calibration are shown in Figure B.3. The 
standard deviation in the vibration amplitude was very low ( $<1 \%$ s.d.) indicating an excellent control by the DUKANE iQ welder. There is a small change in the vibration characteristics at higher amplitudes of the R200 system between 2012 and 2015. This can be attributed to the retexturing operation that were performed to improve sonotrode roughness. There are differences between the R200 and R7200 systems based on the amplitude setting parameter. Hence, all the data included in our paper has been calculated from the calibration curves so that the vibration amplitudes can be compared.

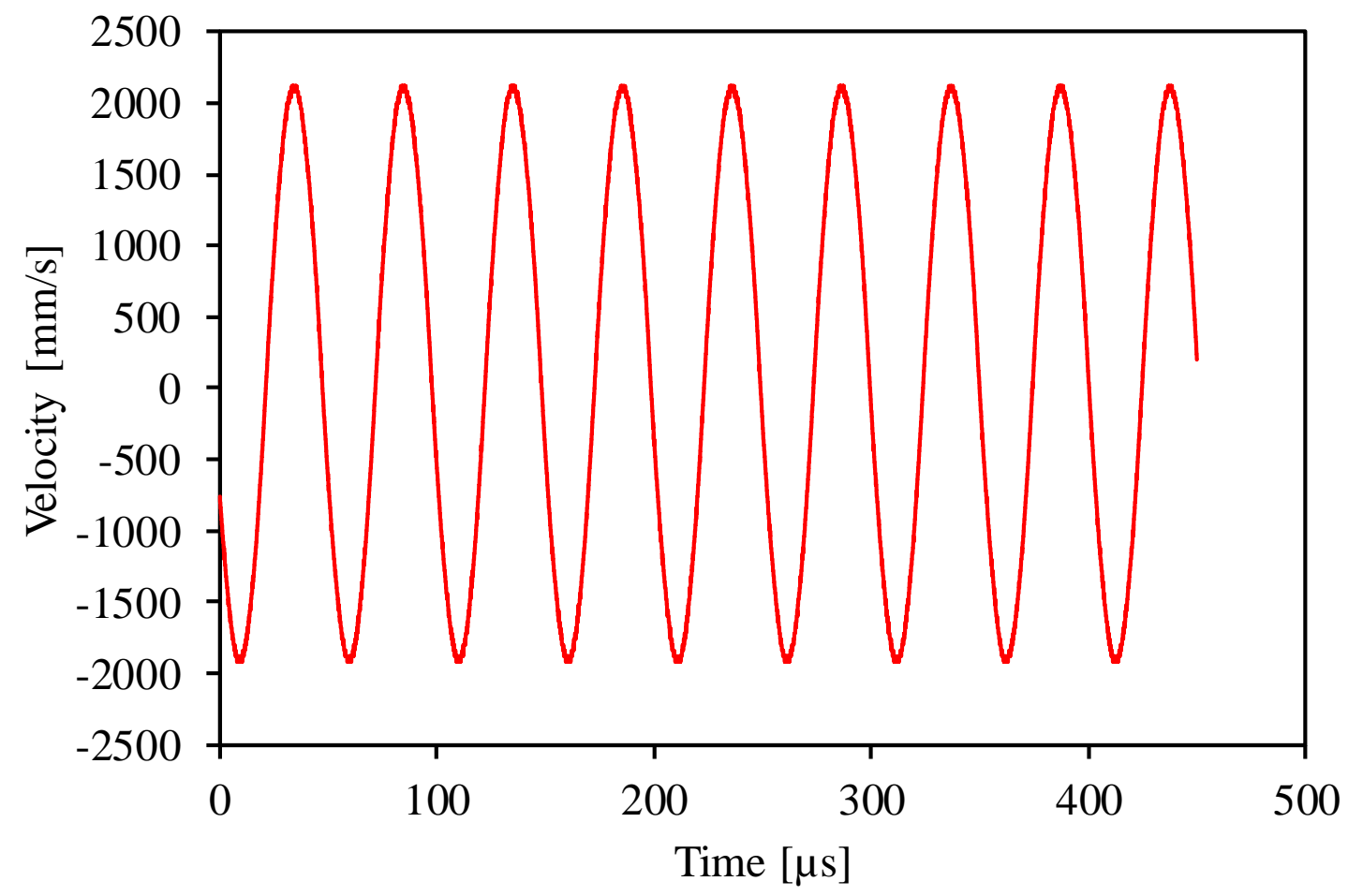

Figure B.2: Change in velocity of sonotrode vibrating at $20 \mathrm{kHz}$ frequency at $70 \%$ amplitude setting. 


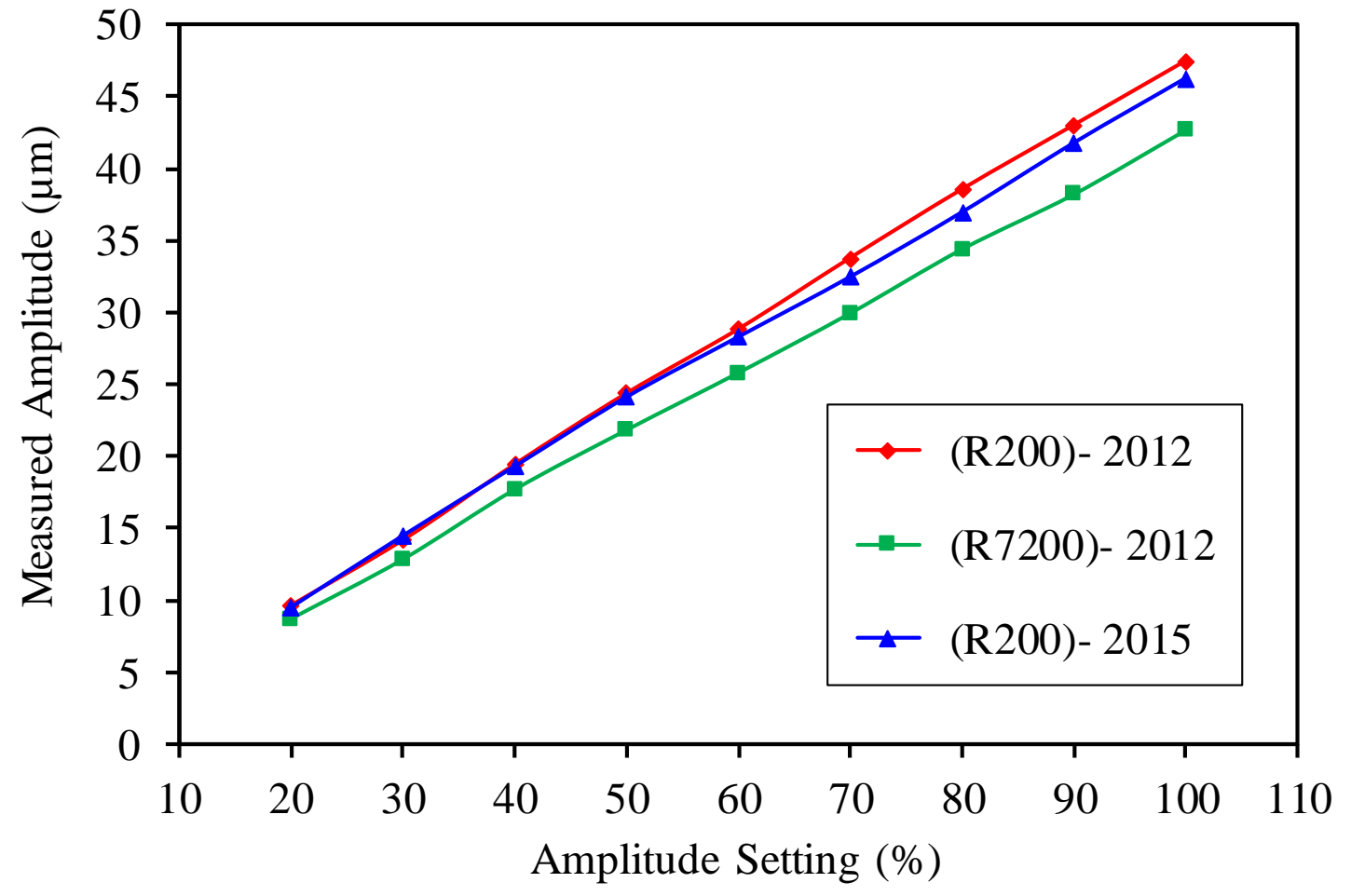

Figure B.3: UAM calibration of the physical vibration amplitude of UAM systems. 